\title{
Using nanotechnology to deliver biomolecules from nose to brain - peptides, proteins, monoclonal antibodies and RNA
}

\author{
Mireya L. Borrajo ${ }^{1}$ (D) - María José Alonso ${ }^{1,2}$
}

Accepted: 20 October 2021 / Published online: 3 November 2021

(c) The Author(s) 2021

\begin{abstract}
There is a growing number of biomolecules, including peptides, proteins, monoclonal antibodies and RNA, that could be potentially used for the treatment of central nervous system (CNS) diseases. However, the realization of their potential is being hampered by the extraordinary difficulties these complex biomolecules have to reach the brain in therapeutically meaningful amounts. Nose-to-brain (N-to-B) delivery is now being investigated as a potential option for the direct transport of biomolecules from the nasal cavity to different brain areas. Here, we discuss how different technological approaches enhance this N-to-B transport, with emphasis on those that have shown a potential for clinical translation. We also analyse how the physicochemical properties of nanocarriers and their modification with cell-penetrating peptides (CPPs) and targeting ligands affect their efficacy as $\mathrm{N}$-to-B carriers for biomolecules.
\end{abstract}

Keywords Nose-to-brain delivery $\cdot$ Intranasal drug administration $\cdot$ Brain delivery $\cdot$ Biomolecules $\cdot$ Nanomedicine . Nanoparticles $\cdot$ Peptides $\cdot$ Proteins $\cdot$ RNA $\cdot$ Cell-penetrating peptides $\cdot$ Targeting ligands

\section{Introduction}

Numerous neurological diseases, including Alzheimer's disease, Parkinson's disease, ischemic stroke and multiple sclerosis, among others, have a great prevalence in society. Estimations indicate that the number of people affected by these disorders is growing worldwide, also related to the increased longevity of the population. Apart from the devastating consequences these diseases have in public health, the economic cost associated with their treatment and palliative care is also a matter of great concern [1-3]. The therapeutic effect several biomolecules have shown offers a promising opportunity to treat these diseases. For example, insulin has been investigated at the clinical level (up to Phase 3, after intranasal administration) as a treatment for the cognitive

María José Alonso

mariaj.alonso@usc.es

1 Center for Research in Molecular Medicine and Chronic Diseases (CiMUS), Universidade de Santiago de Compostela, Av. Barcelona s/n, Campus Vida, 15782 Santiago de Compostela, Spain

2 Department of Pharmacy and Pharmaceutical Technology, School of Pharmacy, Universidade de Santiago de Compostela, 15782 Santiago de Compostela, Spain decline in Alzheimer's disease [4]. A more critical example is the recently approved monoclonal antibody, aducanamab (commercialized as Aduhelm), which was approved for the treatment of Alzheimer's disease [5-8]. However, despite this recent successful result, their difficult access to the central nervous system (CNS) is an important obstacle for the full exploitation of these biomolecules [9]. The brain is protected by highly restrictive barriers, such as the blood-brain barrier (BBB) and the blood-cerebrospinal fluid barrier (BCSFB) [10-12], which are fundamental for the maintenance of the homeostasis of the CNS, and for the prevention of potential toxic compounds. However, as such, this defence mechanism represents an extraordinary barrier for the transport of drugs to the brain [13, 14]. Moreover, the high metabolic activity of these barriers may contribute to the degradation of the drug molecules transported across them $[15,16]$. For decades, researchers have explored a variety of technological approaches to facilitate the transport of biomolecules across these barriers; however, such achievement remains elusive $[17,18]$. An alternative approach to reach the brain that is gaining increasing attention makes use of the nose-to-brain (N-to-B) route. Interestingly, the first studies, exploring this modality of administration using a dye in a rabbit model, were carried out in 1937 [19]. From then on, significant knowledge on the mechanisms of 
transport of molecules across the N-to-B barriers has been generated. As a consequence, it is known that drugs deposited on the olfactory mucosa can be delivered directly into the brain through the olfactory or trigeminal nerves [20,21]. In line with this knowledge, multiple clinical trials are being conducted, some of them with promising results $[22,23]$. Moreover, in the past few decades, nanotechnology has been positioned as a promising strategy for enhancing the N-to-B transport of therapeutic biomolecules [12, 14, 24-29].

Based on this background information, researchers, including members of our group, have published a number of review articles covering different $\mathrm{N}$-to-B delivery strategies $[14,28-31]$. Our objective in this article is not to expand the content of previous reviews, but to concentrate on the N-to-B delivery of biologicals, an emerging field that is expected to gain significant relevance in the near future. Hence, we critically analyse the $\mathrm{N}$-to-B drug delivery options for biologicals with emphasis on those based on nanotechnology. Moreover, we disclose our understanding of the critical features for nanosystems to function as carriers to overcome the $\mathrm{N}$-to-B barrier.

\section{Challenges and barriers for the nose-to-brain delivery of biomolecules}

\section{Pathways for the nose-to-brain delivery of biomolecules}

The mucosa protecting the nasal cavity can be divided into two main anatomical regions, the respiratory epithelium and the olfactory epithelium (Fig. 1). The respiratory epithelium comprises a major part of the nasal cavity, and it is considered the principal entry from the nose to the blood stream [24, 25]. It presents a high degree of vascularization, receiving its blood supply from the maxillary artery [24]. This mucosa consists of a ciliated epithelium covered by a thick mucus layer [24, 25, 32, 33]. On the other hand, the olfactory epithelium is located on the upper region of the nasal cavity, separated from the CNS by the cribriform plate and the lamina propria and is also protected by a mucus layer [34-36]. This region is highly innervated by the olfactory sensory neurons that connect directly with the olfactory bulb [25, 35]. More detailed information regarding nasal cavity anatomy and physiology can be found in previous reviews [29, 36, 37].

Drugs administered intranasally can reach the brain indirectly, upon systemic absorption through the respiratory epithelium and subsequent transport across the BBB, or directly, across the olfactory epithelium and the olfactory nerves. The indirect transport involving systemic absorption is irrelevant for macromolecules due to the complexity of the multiple barriers associated to the systemic biodistribution and transport across the BBB [27, 38-40]. However, the $\mathrm{N}$-to-B route involving the transport across the olfactory mucosa offers a straight-forward access to the brain, as illustrated in Fig. 2 [25, 27]. Three mechanisms have been described for the N-to-B transport: direct internalization into the olfactory nerve, leading to axonal transport; paracellular transport between epithelial cells and across channels near olfactory nerves; and transcellular transport across cells of the olfactory epithelium $[20,21,36,41,42]$. Following these mechanisms, drugs reach the olfactory bulb, from where they can be distributed into the brain [14, 43, 44].

On the other hand, the trigeminal nerve pathway, a less explored route, involves the axonal transport through the trigeminal nerves that innervate both respiratory and olfactory epithelium $[45,46]$. The trigeminal nerves synapse at the trigeminal ganglion, entry the brainstem and are directed to the caudal and rostral regions of the brain $[45,47,48]$.
Fig. 1 Schematic representation of the olfactory and trigeminal nerve position in the nasal cavity, and pathways to different CNS areas. Created with BioRender.com

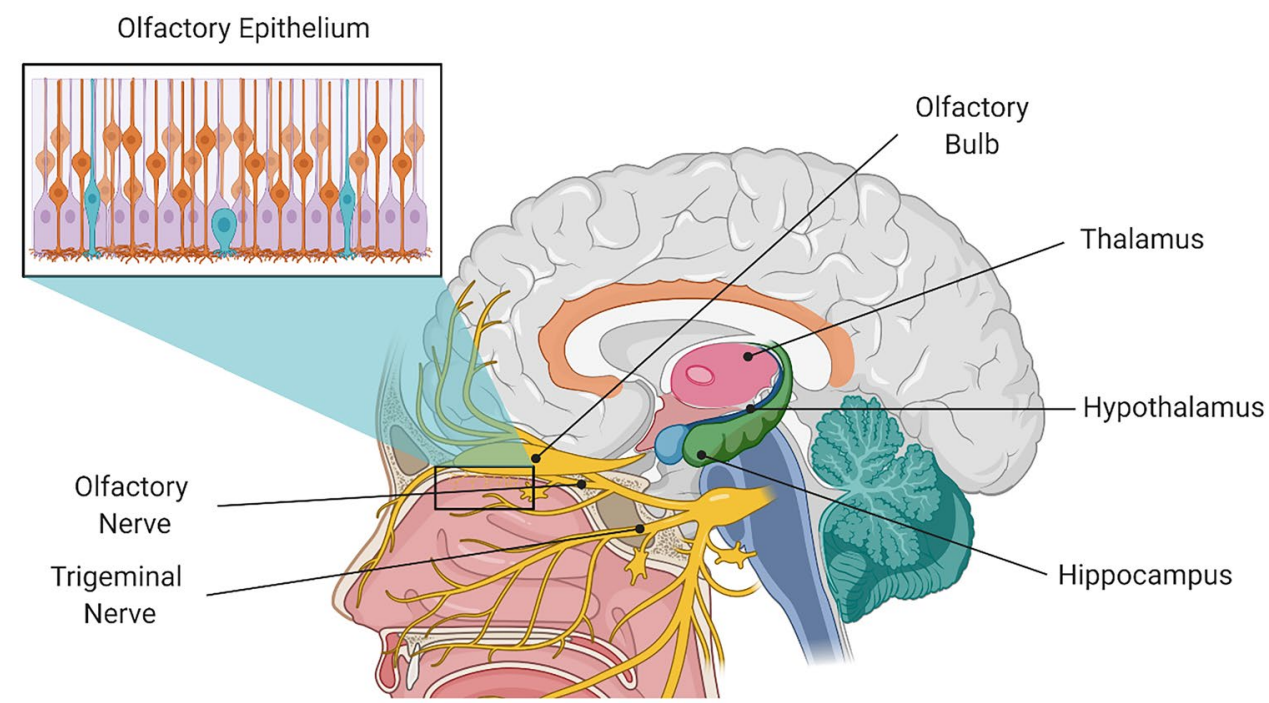


Fig. 2 Possible main pathways for $\mathrm{N}$-to-B transport (in green, olfactory pathway; and in red, trigeminal pathway) [29]. Created with BioRender.com

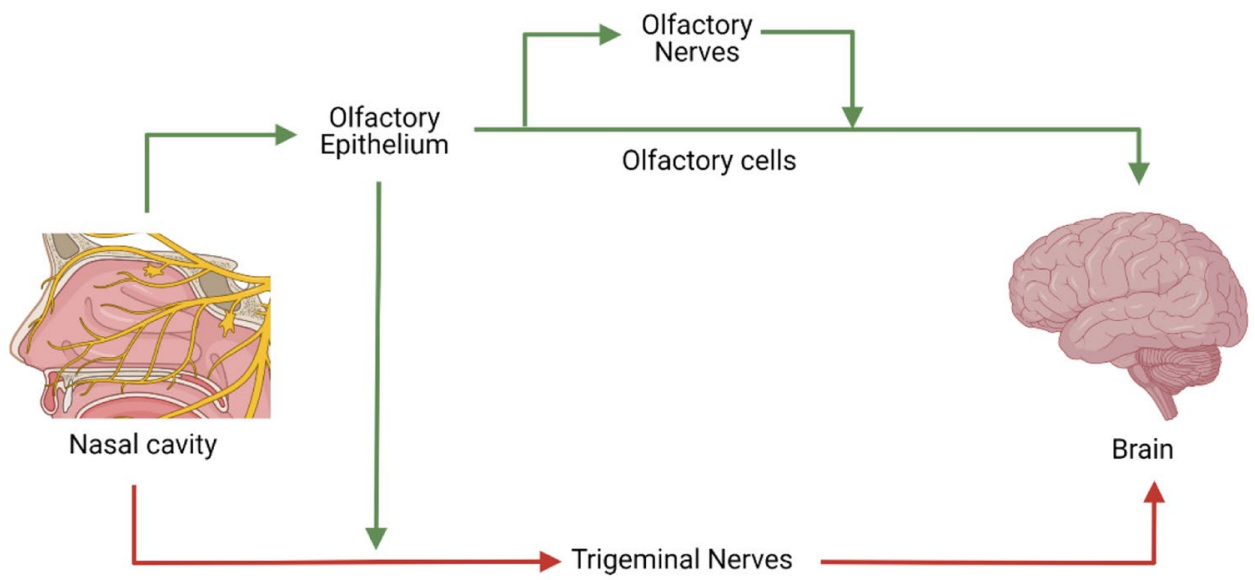

\section{Main challenges in the nose-to-brain transport of biomolecules}

Despite the increasing evidence acquired on the potential of the N-to-B drug delivery, the use of this strategy for the delivery of biomolecules must still face significant challenges before it is proved effective. The factors that influence the $\mathrm{N}$-to-B transport of biomolecules include the physicochemical attributes of the biologicals themselves, and the intrinsic anatomical and physiological barriers of the nasal cavity [31, 49].

The main physicochemical properties influencing the passive diffusion of drugs from N-to-B are molecular weight and lipophilicity. Biomolecules, such as peptides, proteins, or nucleic acids, with a size larger than $300 \mathrm{Da}$ and great hydrophilicity, present a lower N-to-B transport when compared to smaller, more lipophilic molecules [46, 50]. Therefore, these molecules are mainly expected to be transported through a receptor-mediated mechanism of transport, such as specific insulin receptors, which are overexpressed in the olfactory bulb and the hypothalamus; or oxytocin receptors, present in high density in the amygdala and hippocampus [51-56].

On the other hand, there are significant anatomical and physiological barriers preventing the access of drugs from nose to brain. First, the access to the olfactory region, located on the posterior and upper region of the nasal cavity, is not easy and requires the use of specialized delivery devices [57-59]. Second, the surface area of the olfactory mucosa is relatively small compared to the whole nasal mucosa $[60,61]$. Third, the olfactory epithelium presents long nonmobile cilia that, in combination with the mucus secretion and the presence of metabolic enzymes, hinders the N-to-B transport [12, 61-64]. Fourth, the transport across the epithelium by the different mechanisms highlighted above is highly restricted for water-soluble biomolecules, unless they can use specialized transporters, such as the dopamine active transporter or the glucose transporter, among others [65-68].
Finally, the low dosing volume that can be administered (e.g. a maximal dose of $0.4 \mathrm{~mL}$ for humans, a recommended maximum volume of $0.03 \mathrm{~mL}$ for mice) is a limitation when using this route and implies the need for highly optimized formulations if a sufficient dose to produce therapeutic effects is to reach the brain $[69,70]$.

\section{Clinical scenario of nose-to-brain transport of biomolecules}

The clinical trials, specifically aimed at the N-to-B delivery of biomolecules, collected in a ClinicalTrials.gov database, are summarized in Fig. 3 [71]. Among the 196 clinical trials analysed, more than $67 \%$ refer to the administration of biomolecules in the form of a simple aqueous solution. The most clinically tested biomolecule is oxytocin, currently in a Phase 4 study for the indication of autism spectrum disorder and schizophrenia, in Phase 3 for the treatment of Prader-Willi syndrome (PWS) and in Phase 2 for the treatment of dementia and obesity.

The intranasal administration of an insulin aqueous solution has also been widely studied in up to Phase $2 / 3$ clinical trials, as a therapy for Alzheimer's disease, mild cognitive impairment, diabetes, insulin resistance, and Parkinson's disease, among other conditions. Regarding the indication of Alzheimer's disease, initial studies reported improvements in memory and changes in A $\beta 45$ levels [72]. However, subsequent clinical trials were not conclusive for this indication [4, 73]. Additional clinical trials are currently being conducted to elucidate the correlation between administering intranasal insulin and both Alzheimer's disease and mild cognitive impairment. Other highly prevalent diseases extensively studied in clinical trials are diabetes and insulin resistance. Interestingly, clinical studies with participants who presented high hypothalamic insulin sensitivity demonstrated that the insulin performance in the brain enhanced pancreatic insulin secretion $[74,75]$. 


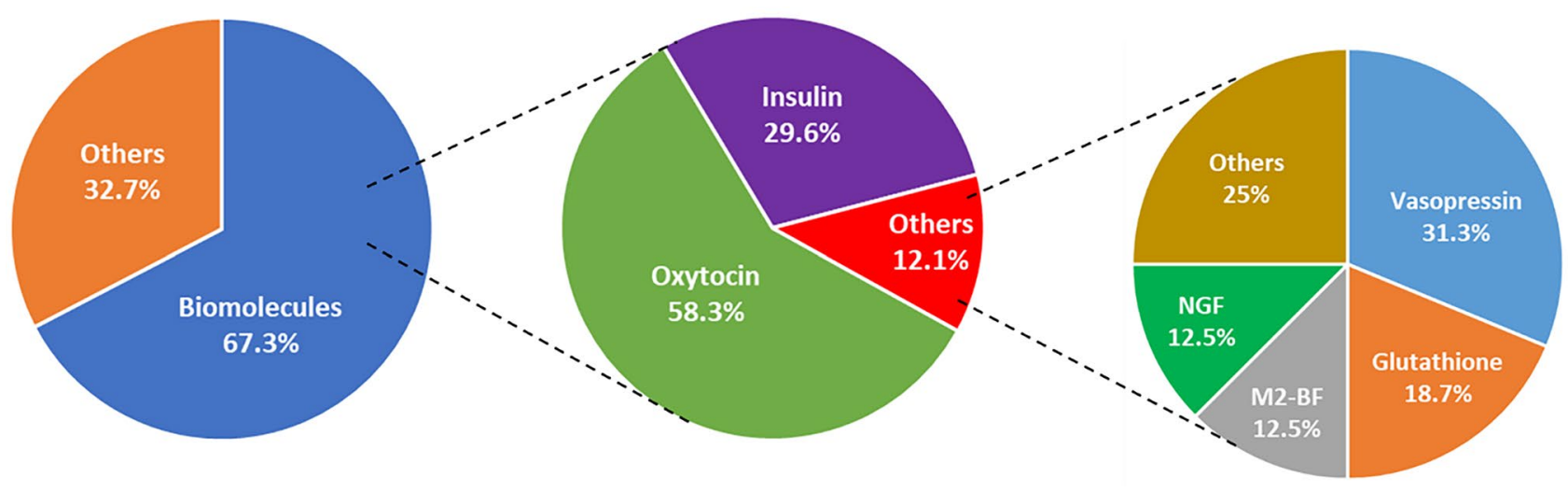

Fig. 3 Summary of the clinical trials involving N-to-B drug delivery of biomacromolecules

Another relevant biomacromolecule currently in clinical trials is vasopressin. Mainly used for social psychology and communication, and pain perception, it shows promising results in an early phase 1 clinical trial [76-78].

To conclude, more than 130 clinical trials with a diversity of biomolecules have been carried out over the last 20 years. However, so far, only oxytocin has reached the final phase 4 clinical trial. In this scenario, it is becoming apparent that an improvement on the access of these biomolecules to the brain is necessary to achieve conclusive results about their potency in the treatment of different brain conditions.

\section{Technological approaches for nose-to-brain delivery of biomolecules}

The increasing interest on the N-to-B delivery of biomolecules is exemplified not only by the significant number of clinical trials being performed, but also by the numerous preclinical studies published presenting evidence of the N-to-B transport (Fig. 4) [79, 80]. A significant increase in the number of publications has been observed from 2010 henceforth. Although the majority of the studies reported refer to simple aqueous solutions of biomolecules, there is an increasing number of publications on delivery strategies for enhancing the N-to-B transport, including penetration enhancers, delivery carriers or a combination of both [29, 31, 44, 81-84].

In the following section, we critically analyse the formulation and delivery strategies explored for the N-to-B delivery of biomolecules.

\section{Mucoadhesion and penetration enhancement}

The use of mucoadhesive polymers has been explored as a way to increase the contact of drugs with the olfactory mucosa and their subsequent diffusion across the olfactory epithelium [12, 25, 32]. However, the enhancement
Fig. 4 Number of publications of nose-to-brain administration of biomacromolecules (Scopus and PubMed database. Keywords: 'nose-to-brain + peptide', 'nose-to-brain + protein', 'nose-to-brain + RNA')

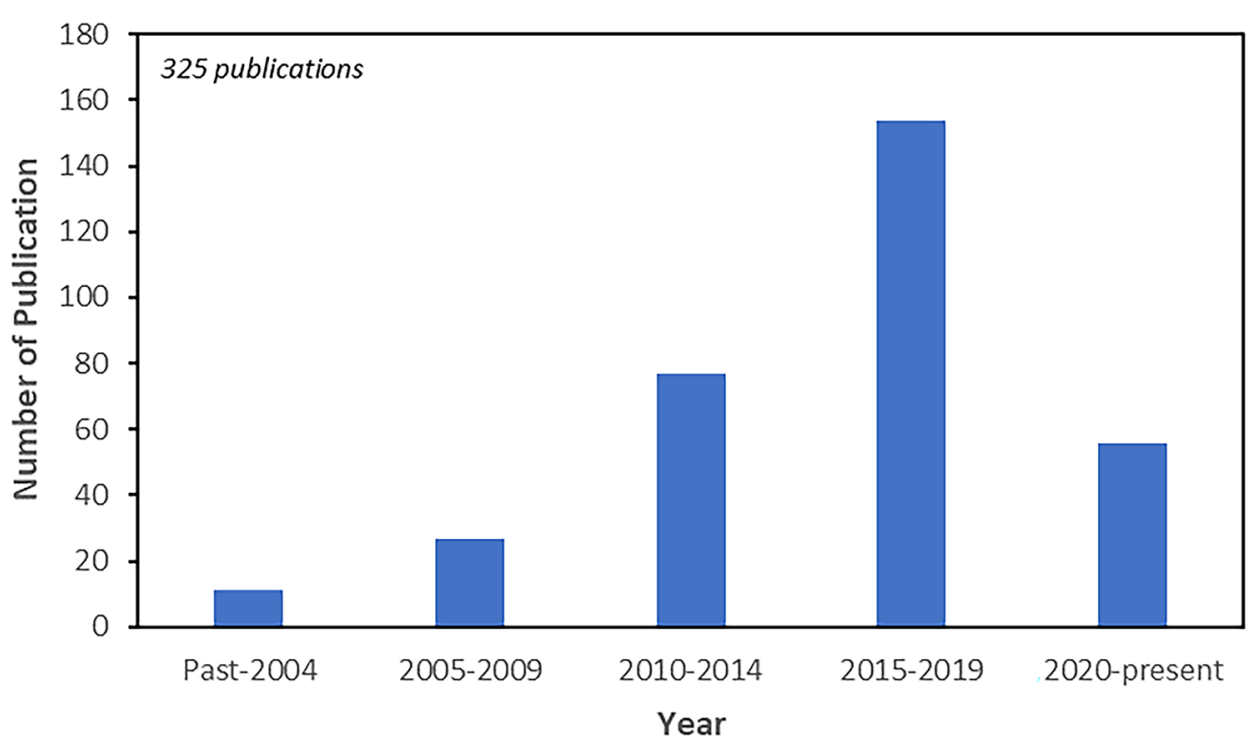


of N-to-B transport of large molecules by use of bioadhesive materials has not been fully validated and only a few examples illustrate this potential mechanism. For example, some authors have reported that the chemical conjugation of hyaluronate, a derivative of hyaluronic acid, with FG loop peptide, a neural cell adhesion molecule-mimetic peptide that is able to decrease the oxidative stress in ischemic episodes, protected the peptide against enzymatic degradation and enhanced its N-to-B delivery [85]. This conclusion was based on the fact that, when using a dose 20 times lower, the hyaluronate conjugate treatment resulted in an infarcted brain area similar to the one shown after treatment with the free FG loop peptide. The authors attributed this positive result to the mucoadhesive properties of hyaluronate; however, the mechanism underlying the transport of the peptide linked to HA remains unclear.

Another mucoadhesive polymer that has been investigated for its potential to increase the $\mathrm{N}$-to-brain access to biomolecules is chitosan, a polysaccharide extensively studied as mucoadhesive and cell penetration agent for N-to-B delivery of small molecules [86, 87]. For example, solutions of chitosan and brain-derived neurotrophic factor (BDNF) reported a 13-fold increase in the accumulation of the protein in the hippocampus [88]. This increased accumulation has been ascribed to the mucoadhesive and penetration enhancement capacity of chitosan.

Overall, while the use of mucoadhesive polymers has been largely reported as a way to enhance the retention of small molecules in the nasal cavity, the translation of the enhanced retention into enhanced adsorption has not been sufficiently validated for biomolecules. This is understandable as the retention of the molecules at the mucosal barrier does not guarantee their subsequent transport to the brain.

The use of penetration enhancers, specially cell penetration peptides (CPPs), is receiving an increasing attention in $\mathrm{N}$-to-B delivery [26, 89]. CPPs are short, positive charge peptides, able to penetrate cellular barriers and facilitate the internalization of co-administered drugs, without the need of interactions with specific receptors [90-92]. Among them, penetratin or pAnt(43-58), a 16-amino-acid peptide that corresponds with the third helix of the Antennapedia homeodomain, a homeoprotein of Drosophila melanogaster, has been the most frequently used [93-95]. Penetratin has two isomers with different cell-penetrating properties: L-penetratin and D-penetratin. In a study where both isomers were nasally administered together with radio-labelled insulin to rats, the levels of insulin detected in the anterior portion of the CSF were higher for L-penetratin [96]. This result was further confirmed in Alzheimer's disease model mice, where co-administration of insulin with L-penetratin reported slower memory loss progression in comparison with the co-administration of insulin with D-penetratin or with the single administration of insulin [97]. Furthermore, differences between both isomers were determined after being co-administered with exedin-4 in Alzheimer's disease model mice: only L-penetratin was able to enhance the N-toB delivery of exedin-4 [98].

In other studies, CPPs were covalently linked to the biomolecule of interest. For example, low molecular weight protamine (LMWP) was linked to various proteins, i.e. bovine serum albumin (BSA), horseradish peroxidase (HRP) and $\beta$-galactosidase. The resulting protein conjugates were found to have a greater access to the brain, as compared to the non-conjugated biomolecules [99]. Similarly, the conjugation of a nine-arginine peptide to Green Fluorescent Protein (GFP) was reported to facilitate the delivery of GFP to the brain [100].

Finally, surfactants have also been proposed as excipients to increase the permeation of molecules across the olfactory mucosa. For example, Pluronic ${ }^{\circledR}$ P85 fused to the protein leptin was reported to enhance its transmembrane penetration and resulted in a higher activation of leptin receptors in the brain than when free leptin was used [101]. Similarly, the surfactant $n$-tridecyl- $\beta$-D-maltoside was also found to increase the permeation of the neuropeptide hexarelin to the brain following nasal administration [102].

Overall, these studies are an indication of the potential interest of penetration and permeation enhancers in combination with biomolecules for improving the $\mathrm{N}$-to-B transport of these biological drugs.

\section{Nanotechnological approaches}

Recently a number of nanotechnologies have been investigated for their capacity to enhance the transport of biomolecules across the olfactory mucosa. Different transport mechanisms can be followed by nanoparticles and their associated molecules when travelling from nose to brain (Fig. 5). These hypothetical mechanisms are as follows: (A) nanoparticles containing drugs and penetration enhancers may cross the olfactory epithelium by a paracellular pathway and may, or may not, release drugs and penetration enhancers in their way to the brain; (B) nanoparticles containing drugs and penetration enhancers may cross the olfactory epithelium by a transcellular way and may, or may not, release drugs and penetration enhancers in their way to the brain; and (C) nanoparticles may be taken up by axons and undergo intra-axonal transport into the olfactory nerve. Nanoparticles crossing the multiple barriers are adequate for RNA delivery, whereas nanoparticles releasing the drug molecules and penetration enhancers at the different levels may be adequate for the delivery of proteins and peptides. This is because the site of action of the peptides and proteins drugs may be located at the extracellular level. However, in the particular case of nucleic acids, they need to be protected while being transported until their internalization inside the brain cells. 


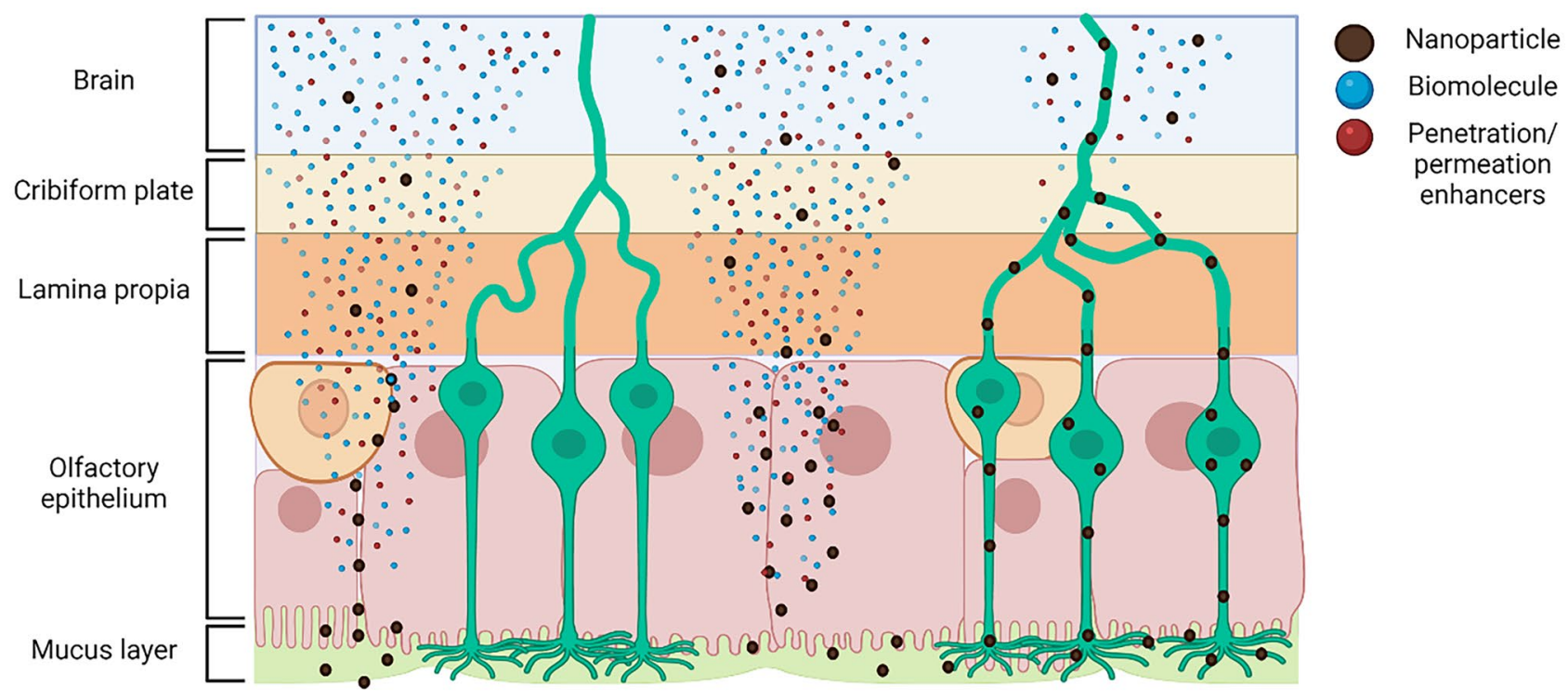

(A)

(B)

(C)

Fig. 5 Schematic representation of the possible mechanisms of transport of nanoparticles (round black), drug molecules (blue spots) across the different barriers. Nanoparticles containing drugs and penetration enhancers may cross the olfactory epithelium by a paracellular (A) or transcellular pathway (B) and may, or may not, release drugs and penetration enhancers (red spots) in their way to the brain. Nanoparticles may be taken up by axons and undergo intra-axonal transport into the olfactory nerve $(\mathbf{C})$. Nanoparticles crossing the

The most common transcellular (B) and intra-neuronal (C) approach that nanoparticles undergo to access the different protective layers of the brain is transcytosis. This phenomenon may involve adsorptive or charge-dependent mechanisms; or receptor-mediated internalization, being this last method more specific and efficient to target the CNS. This mechanism of transport would allow the nanoparticles to undergo through endocytosis, intracellular vesicular trafficking and exocytosis inside the different cellular barriers, aiming to reach their side of action [103-105].

The capacity of nanoparticles to work as carriers for the transport across the different barriers is obviously dependent not only on their physicochemical properties but also on their surface composition, which may influence their bioadhesive behaviour, penetration properties or endocytic uptake (Fig. 6). Below we describe critical information that may guide subsequent advances in the development of N-to-B nanomedicines.

\section{Influence of physicochemical properties of nanocarriers}

Even though the literature does not give a clear guidance in terms of which physicochemical properties are the most suitable for enhancing the N-to-B transport, it is reasonable to assume that particle size and surface charge may have multiple barriers without releasing their cargo are adequate for RNA delivery, whereas nanoparticles releasing the drug molecules and penetration enhancers at the different levels may be adequate for the delivery of proteins and peptides. The transneuronal transport $(\mathbf{C})$ is expected to play a significant role in the delivery of RNA-loaded nanocarriers, whereas the transepithelial transport maybe also be adequate for peptides and proteins. Created with BioRender.com

a fundamental role in the ability of nanocarriers to reach the CNS. Regarding particle size, it is generally accepted that the physiological characteristics of the N-to-B pathways determine the critical size for the nanoparticles (NPs) to be transported through the N-to-B pathway. For example, with regard to the trans-neuron pathway, given that the axons diameter in humans is $100-700 \mathrm{~nm}$, it has been hypothesized that carriers larger than this would not be able to use this route of transport. Based on the fact that the dimension of axons varies between 100 and $200 \mathrm{~nm}$ in different animal species [29, 36, 43, 106], the majority of the nanocarriers disclosed for N-to-B delivery have been designed to have a size between 50 and $150 \mathrm{~nm}$ (Tables 3-5). However, as the trans-neuron transport is not the only N-to-B pathway, other nanocarriers with a mean size of $270 \mathrm{~nm}$, or even $440 \mathrm{~nm}$, have also shown some positive results in in vivo studies [107-109]. For example, using polysorbate- 80 coated polystyrene NPs, it was observed that particle diameters of $100 \mathrm{~nm}$ showed more than a fourfold greater brain uptake than the same system with a $180 \mathrm{~nm}$ mean size. In a separate study, different sizes of polyethylene glycol-polylactic acid (PEG-PLA) NPs were developed; according to their results, mean diameters of $100 \mathrm{~nm}$ showed greater brain accumulation and, in consequence, enhanced therapeutic effect, than nanosystems of $500 \mathrm{~nm}$, in an epilepsy rat model after 
Fig. 6 Nanotechnological approaches for the N-to-B delivery of biomolecules. Incorporation of biomolecules (e.g. peptides, proteins and nucleic acids) into different nanosystems can enhance their effective $\mathrm{N}$-to-B transport, which is driven by (A) the physicochemical properties of the nanocarriers; (B) their bioadhesive nature; $(\mathbf{C})$ their surface modification with different permeation or penetration enhancers; or (D) their surface functionalization with targeting ligands. Created with BioRender.com

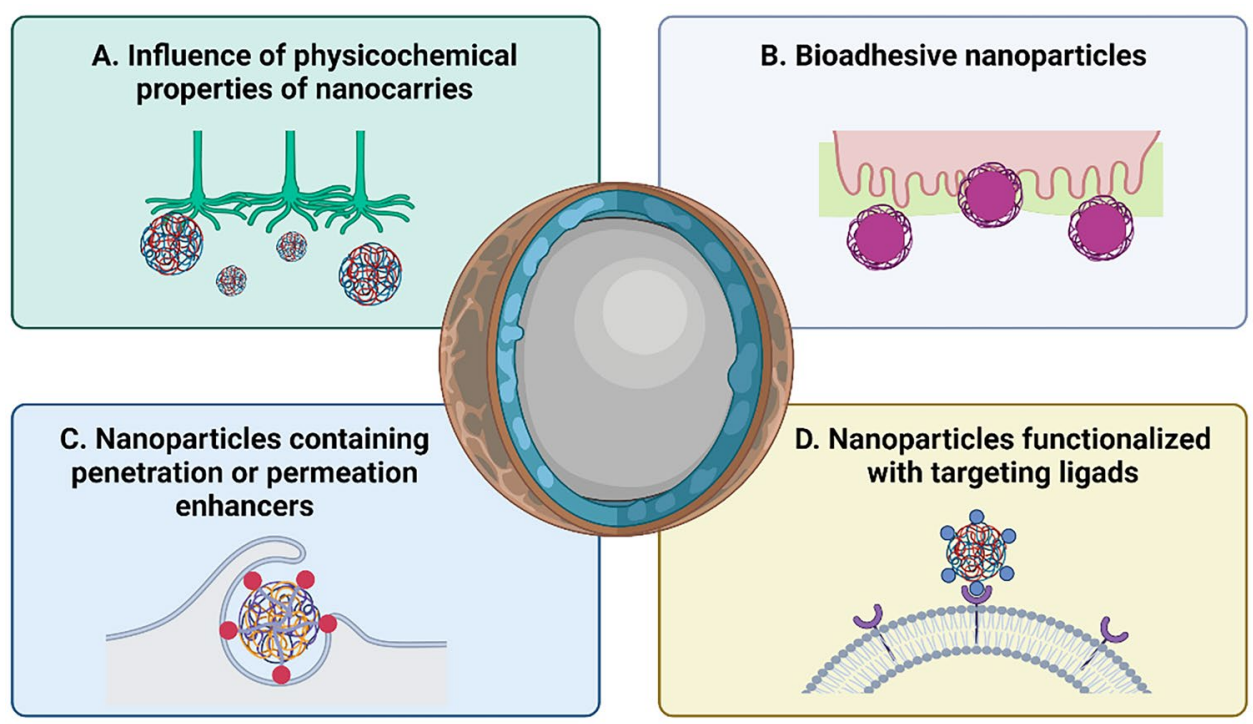

intranasal administration [110]. In a more recent study on the biodistribution of nanoemulsions with different diameter, it was concluded, using fluorescence imaging, that nanosystems with a diameter of $100 \mathrm{~nm}$ were capable to follow both olfactory and trigeminal pathways, while nanocarriers with a larger particle size were not detected on the olfactory bulb [111]. Finally, a report aimed at exploring the influence of the particles chitosan-coated polystyrene NPs (160 and $280 \mathrm{~nm}$ ) showed that, irrespective of their size, their transport to the brain was negligible [112].

A literature analysis of the influence of the surface charge on the capacity of nanocarriers to overcome the N-to-B barrier leads to the conclusion that it is the chemical composition of the surface, rather than its charge, the main factor influencing the interaction and transport of nanoparticles across the olfactory mucosa. In fact, different nanocarriers with surface charges from +57 to $-30 \mathrm{mV}$ have shown significant efficacy in enhancing $\mathrm{N}$-to-B delivery of different biomolecules [108, 113-115]. For example, chitosan (positive charge)- and polysorbate-80 (negative charge)-coated polystyrene NPs were investigated for their transport across the murine olfactory epithelium. The fluorescence imaging results showed that negatively charged nanocarriers were internalized in the olfactory epithelium in a greater extent than the positively charged ones. This might be attributed to the retention of chitosan nanocarriers in the mucus layer of the nasal cavity $[43,112]$. In a more recent study, the brain distribution of fluorescent positive (chitosan-coated poly(lactic-glycolic acid) (PLGA) NPs) and negative (PLGA NPs) nanocarriers was followed after intranasal administration. Even though both NPs were found in different areas of the brain, the trigeminal pathway seems to be the area mainly responsible for the transport of positively charged nanosystems while the negative NPs seem to be transported primarily by the olfactory pathway. Importantly, these differences on the main N-to-B pathway followed could also be attributed to the difference in particle size observed in positive $(213 \mathrm{~nm})$ and negative $(118 \mathrm{~nm})$ NPs [116]. Further studies comparing nanocarriers with different surface charges but maintaining similar particle diameters should be performed to confirm this hypothesis.

Overall, it is clear that the physicochemical properties of nanosystems influence the success of N-to-B delivery of biomolecules, but no clear conclusions can be reached regarding the limits in particle size or surface charge that are more favourable to enhance the N-to-B transport.

\section{Bioadhesive nanoparticles}

Although the interest on increasing the bioadhesion or mucoadhesion of nanocarriers to enhance the N-to-B delivery of biomolecules is still being elucidated, examples of the incorporation of adhesive regents into nanosystems to facilitate N-to-B transport of biomolecules are highlighted in the literature.

Only a few manuscripts have reported the potential positive role of mucoadhesion in the N-to-B transport of nanostructures. For example, some studies reported the incorporation within in situ-forming gels of radioactively labelled siRNA complexed into dendriplexes. After intranasal administration of these Carbopol-containing dendriplexes, the radio-labelled accumulation in the brain detected was greater than the one obtained when using dendriplex or free siRNA [117]. Other materials have been used for the development of nanogels, such as poly( $N$-vinyl pyrrolidone) (PVP), that seem to depict certain mucoadhesive properties [118]. PVPbased nanogels have been studied for the delivery of insulin to the brain. After intranasal administration in mice, twofold 
greater fluorescent levels were detected in the brain, compared with the N-to-B administration of free insulin [119].

Despite these results, it is still unclear what the role of bioadhesion or mucoadhesion on enhancing the delivery of biomolecules to the brain may be. As mentioned in this review article, mucoadhesion properties increase the residence time in the nasal cavity and the further delivery of small molecules to the brain, but the same principle does not apply to biomolecules. In fact, as indicated for chitosan, the mucoadhesive properties of nanoparticles and gels may promote their retention at the mucus level. Further studies need to be performed in order to conclusively elucidate the role of bioadhesion and mucoadhesion on the nanocarriermediated N-to-B transport of biomolecules.

\section{Nanoparticles containing penetration or permeation enhancers}

Based on the observed fact that the co-administration of permeation enhancers or CPPs with biomolecules can enhance their N-to-B transport, some authors have proposed the idea of incorporating CPP as a constituent of nanoparticles. For example, as shown in Table 1, a few studies have used a covalent linkage of CPPs to the nanoparticles. In some cases, a 13 amino acid truncate version of the trans-activator of transcription (Tat) protein of human immunodeficiency virus (HIV-1) was used [120-122]. The benefit of Tat in terms of enhancing the $\mathrm{N}$-to-B transport was assessed upon covalent linking to insulin-loaded PLGA NPs. The brain accumulation of fluorescently labelled Tat-modified NPs, measured by fluorescence microscopy, was 6 times greater than the one obtained using the non-modified NPs [123]. The same approach was applied to PEG-poly ( $\varepsilon$-caprolactone) (PEGPCL) nanomicelles, loaded with different types of siRNA. In all cases, both the therapeutic effect and the brain biodistribution were greater when nanomicelles were modified with Tat than with plain nanomicelles [124-126]. The influence of the Tat density on the surface of PEG-PLA nanomicelles in their transport across the olfactory mucosa was also explored in a different study. The authors determined that micelles with a Tat surface density of $10 \%$ were able to get through trigeminal nerves at a higher extent than those with a lower Tat density. Nanosystems were also observed in the olfactory nerves, but their presence was mainly attributed to their small size, because regardless of the Tat surface density, the mean diameter size was 20-35 nm [127].

A different CPPs mentioned above, LMWP, was also conjugated to fluorescently labelled PEG-PLA NPs. The modified NPs showed a greater brain distribution into cerebrum, cerebellum, olfactory tract and olfactory bulb, also including olfactory and trigeminal nerves, in comparison with nonmodified NPs [128]. These results correlate with previously discussed studies where LMWP were directly fused with different proteins, which enhanced their N-to-B transport [99].

Another CPP used to study the brain biodistribution of fluorescent-dextran-loaded nanomicelles upon nasal administration was a basic peptide composed of arginine, histidine and cysteine (CH2R4H2C). The micelles were based on a hydrophobic derivative (stearyl modification) or on a hydrophilic derivative (PEG-PCL modification) of the CPP. Micelles made with C16-CPP showed accumulation in the olfactory bulb, with no relevant distribution to other brain areas; whereas micelles made of CPP-PEG-PLC showed a broad distribution in the brain. Even though authors concluded that the brain distribution of the hydrophilic derivative suggested that their uptake is mediated by both the olfactory and the trigeminal pathways, this could be also be explained by the positive effect of the PEGylation of the polymer leading to an enhanced diffusion across the brain stroma [129].

Our group has also used a hydrophobic derivative of octarginine (C12-r8) to form nanocomplexes with miRNA. The resulting nanocomplexes were subsequently enveloped with an amphiphilic polymer, poly(glutamic acid)-PEG (PGA-PEG). These enveloped nanocomplexes (ENCPs) were found to transport miRNA to the brain and to modulate its mRNA targets [130].

Importantly, despite the positive results in terms of enhanced transport achieved with the incorporation of CPPs to the nanocarriers, it should be kept in mind that the amount of these compounds may need to be limited in order to avoid potential immunogenicity problems [131, 132].
Table 1 Examples of selected nanosystems modified with CPPs for N-to-B delivery

\begin{tabular}{llll}
\hline Nanosystem & Cell-penetrating peptide & Animal model & Ref \\
\hline PLGA NPs & Tat & Mice & {$[123]$} \\
PEG-PCL nanomicelles & Tat & Rat & {$[124-126]$} \\
PEG-PLA nanomicelles & Tat & Rat & {$[127]$} \\
PGA-PLA NPs & LMWP & Rat & {$[128]$} \\
Nanomicelles & CH2R4H2C & Rat & {$[129]$} \\
Nanocomplexes & C12-r8 & Mice & {$[130]$} \\
\hline
\end{tabular}

$L M W P$ low molecular weight protamine, $P E G$-PCL PEG-poly( $\varepsilon$-caprolactone), PEG-PLA PEG-polylactic acid, PLGA poly(lactic-glycolic acid), PEG-PLA PEG-polylactic acid 
In addition to the so-called CPPs, cationic polymers, notably chitosan, have also been explored for their penetration-enhancing properties in the form of nanoparticles. Chitosan nanoparticles have been used for the N-to-B delivery of different kinds of siRNA as commented in the following section [113, 133]. Hybrid nanocarriers, combining chitosan with manganese or with gold NPs (AuNPs), have also been proven to enhance the delivery of multiple types of RNA to different brain areas [134, 135]. Moreover, chitosan has been used as a coating material for pre-formed nanocarriers. For example, different studies using nanostructured lipid carriers coated with chitosan and containing human insulin-like neurotrophic growth factor-I (hIFG-1) or glial cell-derived neurotrophic factor (GDNF) reported an important accumulation of these factors in the brain, as well as a significant therapeutic effect. Unfortunately, these studies failed to use the adequate comparators (nanocarriers without chitosan) and, hence, the specific role of chitosan in these formulations could not be assessed [136, 137]. Trimethyl-chitosan (TMC), a chitosan derivative with enhanced adhesion properties, was used in the form of a nanocomplex with the neuropeptide, leucine-enkephalin (Leu-Enk). After intranasal administration, the increased delivery to the brain was explained by the electrostatic interaction of the cationic nanoparticles with the brain capillaries, although this qualitative information is very speculative and obtained from a microscopic observation of sections of the mouse brain. The mechanism of action of chitosan for the enhancement of permeation of nanocarrier is still to be elucidated [107].

In addition to these biomaterials, either peptides or polymers, recognized as penetration or permeation-enhancing agents, we must note that the use of surfactants is expected to play a role in the penetration of the nanoparticles into the olfactory mucosa. Overall, these reports are an indication of the potential interest of combining CPPs and other penetration enhancers with NPs.

\section{Nanoparticles functionalized with targeting ligands}

Covalent modification of the nanocarriers' surface with targeting ligands offers an interesting possibility to optimize the N-to-B delivery, as summarized in Table 2. According to our records, the first targeting ligand to be incorporated onto nanocarriers was wheat germ agglutinin (WGA), a lectin with specific binding to $N$-acetyl-D-glucosamine and sialic acid, present on the surface of the epithelial cells of the olfactory mucosa [138-140]. Initial studies on the functionality of PEG-PLA NPs containing vasoactive intestinal peptide reported a significantly higher brain accumulation, in comparison with the one found using unmodified NPs [141]. Further studies intended to elucidate the brain
Table 2 Examples of selected nanosystems modified with targeting ligands for $\mathrm{N}$-to-B delivery

\begin{tabular}{llll}
\hline Nanosystem & Targeting ligand & Animal model & Ref \\
\hline PEG-PLA NPs & WGA & Mice/Rats & {$[141-143]$} \\
PEG-PLGA NPs & WGA & Rats & {$[144]$} \\
PEG-PLGA NPs & STL & Rats & {$[146,147]$} \\
PEG-PLGA NPs & OL & Mice/Rats & {$[149,150]$} \\
Cubosomes & OL & Rats & {$[151]$} \\
PEG-PCL NPs & Lf & Mice & {$[155]$} \\
PEG-PLGA NPs & RVG29 & Rat & {$[157]$} \\
Au-Fe ${ }_{2} \mathrm{O}_{3}$ NPs & T7 & Mice & {$[134]$} \\
AuNPs & D1 & Rat & {$[158]$} \\
\hline
\end{tabular}

$\mathrm{Au}-\mathrm{Fe}_{2} \mathrm{O}_{3}$ gold-iron oxide, $\mathrm{AuNPs}$ gold nanoparticles, $L f$ lactoferrin, NPS nanoparticles, $O L$ odorralectin, $P E G-P C L$ PEG-poly ( $\varepsilon$-caprolactone), PEG-PLA PEG-polylactic acid PEG-PLGA PEGpoly(lactic-glycolic acid), $P L G A$ poly(lactic-glycolic acid), $R V G 29$ rabies virus glycoprotein, STL Solanum tuberosum lectin, WGA wheat germ agglutinin

biodistribution of these nanocarriers, indicated that the accumulation was particularly noticeable in the olfactory bulb, which suggested their transport through the olfactory pathway [142]. WGA-functionalized PEG-PLA nanoparticles were also applied to the N-to-B transport of miRNA-132. The results obtained using fluorescence imaging showed an enhanced accumulation of the functionalized DiR-labelled nanocarriers, both in Alzheimer's disease mice and ischemic rat models [143]. WGA-functionalized PEG-PLA NPs were also applied to the N-to-B delivery of the NR2B9c peptide, in an ischemic stroke rat model [144]. This study found a greater reduction on the infarcted area when compared to the one obtained for the unmodified nanocarrier.

Besides WGA, other lectins have been proven to facilitate the N-to-B delivery of biomolecules by modifying the surface of the nanocarriers. For example, Solanum tubersum lectin (STL), a glycoprotein that binds to $N$-acetyl-Dglucosamine of the nasal cavity epithelium [140, 145], has been reported to enhance the transport of PEG-PLGA NPs loaded with a fluorescent probe to the brain. Indeed, the brain uptake measured by fluorescence imaging was 2.5 -fold greater compared to the unmodified NPs [146]. Additionally, the same group loaded basic fibroblast growth factor (bFGF) into PEG-PLGA NPs functionalized with STL. This study showed a threefold increase of the AUC of bFGF, when compared to unmodified nanocarriers [147].

Despite these positive results, lectins have been reported to exhibit a certain immunotoxicity and this fact has encouraged researchers to explore small lectin-like peptides. For example, Odorranalectin (OL), a $1.7 \mathrm{kDa}$ small peptide originally obtained from frog skin, which was found to 
specifically bind to L-fucose overexpressed in the olfactory epithelium [145, 148], was used to functionalize PEG-PLA nanoparticles. Using fluorescence imaging, it was observed that the transport of fluorescently labelled functionalized NPs was superior than the one obtained with the unmodified nanocarrier [149]. Moreover, the same authors analysed the potential of this system for the N-to-B delivery of the peptide urocortin, which is indicated in the treatment of neurological disorders. The in vivo results obtained in a Parkinson's disease mice model showed a neurological recovery, which was associated to the significant transport of urocortin [150]. Similar brain biodistribution results were obtained with PEGylated cubosomes functionalized with OL and loaded with Gly14-Humanin (S14G-HN). An increase in the drug concentration in the brain as well as a significant enhancement of the therapeutic effect after the surface modification was observed [151].

One of the most frequently used targeting moieties that has been incorporated on the surface of nanoparticles is the glycoprotein lactoferrin (Lf), a ligand of the lactoferrin receptor (LfR) highly expressed in brain endothelial cells and neurons [152-154]. The results of an in vivo fluorescence imaging study using fluorescently labelled PEG-PCL NPs indicated that Lf enhanced the accumulation of the NPs in the brain. Moreover, when these Lf-functionalized PEG-PCL NPs were applied to the N-to-B delivery of NAP peptide, a greater neuroprotective effect after ligand modification was reported [155].

Other peptidic moieties have been used for enhancing $\mathrm{N}$-to-B delivery. A small portion of the rabies virus glycopeptide (RVG29), responsible for the cellular entry and virus fusion, efficiently binds to the nicotinic acetylcholine receptor (NAchR), that is present in CNS cells [156]. It has been proven that RVG29 in combination with PEG-PLGA NPs significantly enhances brain delivery of miRNA-124. Curiously, both RVG29 and PEG are needed to obtain the highest miRNA accumulation and therapeutic effect [157].

Inorganic NPs have also been modified with different targeting peptides. T7 peptide (Ac-Cys-His-Ala-Ile-TyrPro-Arg- $\mathrm{CONH}_{2}$ ) in combination with gold-iron oxide NPs ( $\mathrm{Au}-\mathrm{Fe}_{2} \mathrm{O}_{3} \mathrm{NPs}$ ) showed greater accumulation in the brain than unmodified nanosystem. The same result was obtained when using a modification of D1 peptide (Gln-Ser-His-TyrArg-His-Ile-Ser-Pro-Ala-Gln-Val) of gold NPs (AuNPs), even though comparison with the unmodified carrier was not reported [158].

More relevant studies have been developed to check the efficacy of targeting ligands. These studies were mainly performed using fluorescent or radio-labelled probes, or small molecules [159-163]. They concluded that specific ligands, i.e. lectins, glycoproteins, and glycopeptides, with affinity for epithelial cells or neurone receptors enhance the N-to-B transport of nanoparticles loaded with biomolecules.

\section{Illustrative nanotechnologies for nose-to-brain delivery of biomolecules}

As reported in the previous section, different types of nanocarriers have been designed to improve the protection of biomolecules from degradation and their N-to-B transport [164-166]. Here, we describe a number of selected nanotechnology-based formulations containing specific biomolecules (peptides, proteins and nucleic acids) that were found to be effective in the treatment of neurological diseases.

\section{Peptides}

The delivery of peptides to the brain is a topic that has attracted increasing attention over the past decades, due to their pharmacological value for the treatment of CNS diseases, including neurodegenerative diseases, cancer or ischemic strokes [167-169]. Nanotechnology offers the possibility to overcome the challenges that peptides face to achieve N-to-B transport (Table 3) [28, 170].

Most of the in vivo studies involving the use of peptides loaded onto nanocarriers were aimed at the treatment of Alzheimer's disease (AD). The goal of the early studies, performed in 2007, was to investigate the potential of WGAfunctionalized PEG-PLA NPs to enhance the transport of the vasoactive intestinal peptide. The results showed that the peptide concentration in the brain was 7 times higher when associated to the NPs as compared to the free peptide [141]. A peptide named humanin derivative was associated to PEGylated cubosomes $(93 \mathrm{~nm}$ ) functionalized with OL peptide. The results obtained by fluorescence imagining in an $\mathrm{AD}$ rat model indicated that the OL functionalization led to a 2.6-fold increase in the access of cubosomes to the brain. This increased brain delivery translated into a significant enhancement of the therapeutic effect [151]. The NAP neuropeptide was loaded into Lf-functionalized PEG-PCL NPs, of $90 \mathrm{~nm}$, and the N-to-B transport was assessed by fluorescence imagining in an $\mathrm{AD}$ rat model. The results indicated that the Lf functionalization of the NPs led to their enhanced transport to the brain, which correlated with a deceleration of memory loss [155]. Recently, some authors reported that simple nanogels made of PVP with a particle size of $90 \mathrm{~nm}$ and negative surface charge could be used for the enhanced delivery of insulin to the brain. The accumulation of fluorescent-labelled insulin in the brain was visualized by fluorescence microscopy and its activity was measured by Akt activation levels, in an AD mice model [119]. Although the authors hypothesized different potential mechanisms for the transport of the nanogels across the N-to-B barriers, the study did not provide direct and quantitative evidence of the mechanisms involved in the transport. 
Table 3 Overview of selected nanocarrier systems for peptide N-to-B delivery

\begin{tabular}{|c|c|c|c|c|c|c|c|}
\hline Nanosystem & Peptide cargo & Disease & Size $(\mathrm{nm})$ & Z-Pot $(\mathrm{mV})$ & $\begin{array}{l}\text { Targeting } \\
\text { molecule }\end{array}$ & Animal model & Ref \\
\hline PEG-PLA NPs & VIP & $\mathrm{AD}$ & $\sim 120$ & - & WGA & Mice & [141] \\
\hline PEGylted cubosomes & S14G-HN (humanin derivative) & $\mathrm{AD}$ & 93 & -14 & $\mathrm{OL}$ & Rats & [151] \\
\hline PEG-PCL & NAP & $\mathrm{AD}$ & 88 & -24 & $\mathrm{Lf}$ & Mice & [155] \\
\hline PVP nanogels & Insulin & $\mathrm{AD}$ & 90 & -25 & - & Mice & [119] \\
\hline PEG-PLGA & Urocortin & $\mathrm{PD}$ & 115 & -20 & OL & Rats & [150] \\
\hline Gelatin NLC & SP & $\mathrm{PD}$ & 172 & -30 & - & Rats & [114] \\
\hline D,L-PLA NPs & $\mathrm{TRH}$ & Epilepsy & 108 & - & - & Rats & [110] \\
\hline PEG-PLGA & NR2B9c & Ischemia & 139 & -23 & WGA & Rats & [144] \\
\hline$N$-trimethyl chitosan NPs & Leucine-enkephalin & Pain & 443 & +15 & - & Mice & [107] \\
\hline Oil-in-water nanoemulsion & CsA & - & 272 & +57 & - & Rats & [108] \\
\hline
\end{tabular}

$A D$ Alzheimer's disease, $C s A$ cyclosporine-A, $L f$ lactoferrin, $N C L$ nanostructured lipid carriers, $N P s$, nanoparticles, $O L$ odorranalectin, $P D$ Parkinson's disease, $P E G$-PCL PEG-poly ( $\varepsilon$-caprolactone), $P E G$ - $P L A$ PEG-polylactic acid, $P E G$ - $P L G A$ PEG-poly(lactic-glycolic acid), $P L A$ polylactic acid, $P V P$ poly $(N$-vinyl pyrrolidone), $S P$ substance $\mathrm{P}, T R P$ thyrotropin-releasing hormone, $V I P$ vasoactive intestinal peptide, $W G A$ wheat germ agglutinin

Some peptides have also been explored for the treatment of Parkinson's disease (PD). For example, the urocortin peptide, capable of restoring nigrostriatal function, was loaded into PEG-PLGA NPs functionalized with OL and administered intranasally in a PD model. The results reported a six- and threefold increase in the therapeutic effect in comparison with intranasal administration of the free peptide or the unmodified NP, respectively [150]. A peptide named substance $\mathrm{P}$, intended to protect dopamine neurons from neurotoxicity, was loaded into gelatin-cored nanostructured lipid carriers (NLCs) (170 nm, negative surface charge) and assayed in a PD rat model. The results obtained following nasal administration, showed an increase in the efficacy, assessed by quantifying rotational behaviour and levels of proteins related to PD [114].

Some peptides associated to nanocarriers have also been proposed for the treatment of epilepsy. For example, the anticonvulsant thyrotropin-releasing hormone (TRH) was associated to WGA-functionalized PLA NPs $(100 \mathrm{~nm})$ and labelled with a fluorescent marker. Following nasal administration to epileptic rats, the NPs were found to be able to reach the brain and suppress seizures [110]. The NR2BPc peptide, of potential interest for the treatment of ischemia and prevention of strokes, was loaded into WGA-functionalized PLA-PEG NPs (140 nm, and negative surface charge). Following intranasal administration of this formulation to an ischemic rat model, a significant reduction in the size of the infarcted area was reported [144].

The peptide leucine-enkaphalin, associated to trimethyl chitosan NPs (> $400 \mathrm{~nm}$, positive charge) was explored for pain relief purposes. The peptide was labelled with a fluorescent tag for the evaluation of its biodistribution. Following intranasal administration, an increased antinociceptive effect was reported, along with higher brain accumulation for the nanoformulation, as compared to the free drug [107].
Finally, cyclosporine-A (CsA), which has been reported to exhibit neuroprotective properties, has been formulated as a nanoemulsion ( $270 \mathrm{~nm}$ and a positive surface charge) made of flax-seed oil, also known for its neuronal regulating characteristics. A significant brain accumulation of CsA was observed following intranasal administration, a fact that was attributed to a direct N-to-B uptake [108].

\section{Proteins}

The nanotechnological strategies adapted for proteins are similar to those used for peptides (Table 4) [171, 172]. The most frequently tested protein as a cargo of different nanocarriers is basic fibroblast growth factor (bFGF), which depicts neuroprotective effects in different brain-related diseases. For example, bFGF associated to functionalized STL-PEG-PLGA NPs (120 nm and negative surface charge) was administered intranasally in an AD mice model. The results showed that loaded NPs enhanced 1.5 times the AUC of radio-labelled-bFGF compared to free protein, and the modification with the targeting ligand further increases the value of AUC up to 3 times more, as described above [147]. The same protein, bFGF encapsulated into gelatin NLC (128 and negative surface), containing phospholipids, cholesterol, and Poloxamer 118, was tested in an ischemia rat model. The results highlighted a 1.5 times greater protein accumulation in different brain areas, when compared with intravenous administration, as well as enhanced therapeutic response [173]. The same nanocarrier was used to deliver bFGF for the treatment of PD. The results showed high protein levels in different areas of the brain, including the olfactory bulb and striatum, and enhancement of their therapeutic effect after intranasal administration in a PD rat model, as 
Table 4 Overview of selected nanocarrier systems for proteins N-to-B delivery

\begin{tabular}{|c|c|c|c|c|c|c|c|}
\hline Nanosystem & Peptide cargo & Disease & Size (nm) & Z-Pot (mV) & $\begin{array}{l}\text { Targeting } \\
\text { molecule }\end{array}$ & Animal model & Ref \\
\hline PEG-PLGA NPs & bFGF & $\mathrm{AD}$ & 120 & -32 & STL & Rat & {$[147]$} \\
\hline Gelatin NLCs & bFGF & Ischemia & 128 & -15 & - & Rat & [173] \\
\hline Gelatin NLCs & bFGF & PD & 172 & -28 & - & Rat & {$[115]$} \\
\hline CS NLCs & GDNF & PD & 137 & +30 & - & Rat & {$[137]$} \\
\hline CS NLCs & hIFG-1 & - & 114 & +28 & - & Mice & {$[136]$} \\
\hline PEG-PLA polymersomes & BDNF & Neuro-inflammation & 270 & -20 & - & Mice & [109] \\
\hline
\end{tabular}

$A D$ Alzheimer's disease, $B D N F$ brain-derived neurotrophic factor, $b F G F$ basic fibroblast growth factor, $C S$ chitosan, $G D N F$ glial cell-derived neurotrophic factor, $h I F G-1$ human insulin-like neurotrophic growth factor-I, $N L C$ nanostructured lipid carriers, $N P s$ nanoparticles, $P D$ Parkinson's disease, PEG-PLA PEG-polylactic acid, PEG-PLGA PEG-poly(lactic-glycolic acid), STL Solanum tuberosum lectin

compared with free protein and intravenous administration of the nanoencapsulated protein [115].

The glial cell-derived neurotrophic factor (GDNF), also applied to Parkinson's disease, has been entrapped in chitosan NLCs, using a combination of solid and liquid lipids. Their intranasal administration in PD model rats resulted in a meaningful behavioural improvement [137]. These authors fluorescently labelled these nanosystems for studying the $\mathrm{N}$-to-B transport of human insulin-like neurotrophic growth factor-I (hIFG-I). The fluorescent images indicated a high accumulation in the brain, with diffusion and penetration into different brain areas. Moreover, NLCs were strongly detected in the olfactory tract, a result that was attributed to the mucoadhesive properties of chitosan [136].

The brain-derived neurotrophic factor (BDNF), encapsulated into PEG-PLA polymersomes $(270 \mathrm{~nm}$ and a negative surface charge) was co-administered with simvastatin intranasally in a neuro-inflammation mice model. The results showed a significant reduction of cytokine levels and microglial activation in different brain areas when both drugs are co-administered, compared to single-drug nanoencapsulated administration [109].

\section{Monoclonal antibodies}

Among the different protein-based therapies, monoclonal antibodies (mAbs) have gained particular attention over the past decades, resulting in an increasing amount of therapeutic antibodies on clinical trials and even in the market [174-176]. Interestingly, FDA recently approved the use of a monoclonal antibody, aducanumab (marked as Aduhelm), for the treatment of $\mathrm{AD}$, thus paving the way to further development of antibody-based treatments for CNS conditions [7, 8]. Despite the interest of mAbs for the treatment of neurological diseases, to our knowledge, the use of nanotechnology for the N-to-B delivery of these molecules has not been explored. The only report we have found makes use of the mAb anti-EPH3 as a targeting ligand attached to PLGA NPs coated with trimethyl chitosan. This approach relies on the fact that anti-EPH3 targets a membrane receptor overexpressed in the stroma and vasculature of gliomas. The NPs were loaded with temozolomide and administered intranasally in a glioma rat model. Higher brain accumulation of NPs was determined by fluorescence imaging after they were functionalized with anti-EPH3 antibody, compared with unfunctionalized NPs. Moreover, median survival time and apoptosis of glioma cells was significantly enhanced upon treatment with the functionalized NPs [177].

\section{RNA (siRNA, miRNA)}

Among the different types of biomolecules, RNA constructs may be one of the more challenging to be delivered through N-to-B pathways [178, 179]. In addition to the challenges described for the delivery of peptides and proteins, the RNA molecules need to reach the intracellular space in order to execute their action. To achieve this, RNA molecules must remain associated to the NPs until reaching the intracellular target and the NPs must be able to cross intact the N-to-B barriers (as shown in Fig. 5) [180, 181]. Considering all these requirements, different nanocarriers had been designed for the efficient N-to-B transport of nucleic acids (Table 5).

Among the different types of RNAs, siRNA has received the greatest attention for the treatment of neurological pathologies and, hence, for the N-to-B delivery. One of the first nanocarriers developed for the delivery of siRNA molecules (including FAM-siRNA, siRNA Raf-1 and siRNA TFN- $\alpha$ ) was the Tat-modified PEG-PCL nanomicelles (size of 50-160 nm and positive surface charge) [124-126]. This nanocarrier could efficiently transfer the FAM-siRNA molecules into the olfactory and trigeminal nerves [124]. Further studies with the same nanosystems involved the encapsulation of both siRNA Raf-1 and camptothecin (CPT) for the treatment of glioblastoma. The in vivo results showed a significant accumulation of fluorescent siRNA in the brain, which translated into a greater survival time and tumour reduction [125]. Similarly, siRNA Gal-1-loaded chitosan NPs (140 nm and positive surface charge) were 
Table 5 Overview of selected nanocarrier systems for RNA N-to-B delivery

\begin{tabular}{|c|c|c|c|c|c|c|c|}
\hline Nanosystem & RNA cargo & Disease & Size $(\mathrm{nm})$ & Z-Pot (mV) & Targeting molecule & Animal model & Ref \\
\hline PEG-PCL nanomicelles & FAM-siRNA & - & 50 & +10 & Tat & Rat & {$[124]$} \\
\hline PEG-PCL nanomicelles & siRNA Raf-1 & Gioblastoma & 160 & +9 & Tat & Rat & {$[125]$} \\
\hline CS NPs & siRNA Gal-1 & Glioblastoma & 141 & +32 & - & Mice & {$[133,182]$} \\
\hline PEG-PCL nanomiclles & siRNA TNF- $\alpha$ & Ischemia & 62 & +19 & Tat & Rat & {$[126]$} \\
\hline CS NPs & siRNA HTT & $\mathrm{HD}$ & $104-205$ & $+43-55$ & - & Mice & [113] \\
\hline PEG-PLGA NPs & $\operatorname{miR}-124$ & Ischemia & 204 & - & RVG29 & Rat & {$[157]$} \\
\hline PEG-PLA NPs & $\operatorname{miR}-132$ & AD/Ischemia & 191 & -25 & WGA & $\begin{array}{l}\text { Mice/ } \\
\text { Rat }\end{array}$ & {$[143]$} \\
\hline PEG-PGA-r8-C12 NCXs & $\operatorname{miR}-132$ & $\mathrm{AD}$ & 96 & +4 & - & Mice & {$[130]$} \\
\hline $\mathrm{Au}-\mathrm{Fe}_{2} \mathrm{O}_{3} \mathrm{NPs}$ & miR-100 and antimiR-32 & Glioblastoma & 50 & +4 & $\mathrm{~T} 7$ & Mice & {$[134]$} \\
\hline
\end{tabular}

$A D$ Alzheimer's disease, $\mathrm{Au}-\mathrm{Fe}_{2} \mathrm{O}_{3}$ gold-iron oxide, $\mathrm{CS}$ chitosan, $\mathrm{FAM}$ 6-carboxyfluorescein-aminohexyl, Gal-1 Galectin-1, $H D$ Huntington's disease, HTT huntingtin, NCXs nanocomplexes, NPs nanoparticles, PEG-PCL PEG-poly ( $\varepsilon$-caprolactone), $P E G$ - $P G A$ PEG-polyglutamic acid, PEG-PLA PEG-polylactic acid, PEG-PLGA PEG-poly(lactic-glycolic acid), $r 8$-C12 octaarginine-lauric acid, $T N F$ - $\alpha$ tumour necrosis factor- $\alpha$

administered intranasally in a glioblastoma mice model. The results showed an overall increase in the survival rate of mice, affecting the tumour microenvironment composition, polarization of macrophages, or tumour vasculature. Moreover, the combination of siRNA Gal-1-loaded chitosan NPs with temozolomide or PD-1 blocking resulted in a significant synergic effect, increasing survival rate [133, 182].

The use of siRNA-loaded NPs for the treatment of a neurodegenerative disease, i.e. Huntington's disease (HD), has also been explored. siRNA anti-huntingtin (HTT)-loaded chitosan-modified NPs were administered intranasally in a HD mice model. Hydrophobic modifications of siRNA led to a minor silencing effect in some brain areas, whereas hydrophobic modified siRNA-loaded chitosan NPs led to a reduction in the HTT mRNA and protein levels [113].

Finally, siRNA TNF- $\alpha$-loaded Tat- modified PEGPCL nanomicelles (62 $\mathrm{nm}$ and positive surface charge) were administered intranasally in an ischemic stroke mice model, and the result of this treatment was a reduction of the infarcted area [126].

Different nanocarriers had been explored for the delivery of different types of miRNA for the treatment of diverse CNS conditions. For example, PEG-PLGA NPs, chemically modified with RVG29, were developed for the intranasal delivery of miR-124 in an ischemia rat model. Interestingly, both targeting ligand and PEG chain were identified as key elements for the successful delivery of miRNA to the brain, significantly improving the modulation of its target mRNAs and the neurobehavioural score along with a reduction in the infarcted brain area [157]. In a different study, the potency of miR-132 for the treatment of AD and ischemia was evaluated in mice and rats, respectively. miR-132 was complexed with spermidine, and the resulting complex was encapsulated onto PEG-PLA NPs (191 nm and negative surface charge) chemically modified with WGA. In an AD mice model, significant improvement in terms of behaviour as well as decreasing $\mathrm{A} \beta$ levels were reported. Moreover, enhanced neurobehavioural score and reduction on infarcted brain area were achieved on an ischemic rat model, proving the promising effect of miR-132 for the treatment of different CNS conditions [143].

An enveloped nanocomplexes (ENCPs) technology was developed in our lab, consisting on miRNA-132 complexed to r8-C12 and enveloped with PEG-polyglutamic acid (PGA) (96 nm, neutral surface charge). This formulation resulted in a significant modulation of mRNA targets in the olfactory bulb and the hippocampus after intranasal administration [130].

Combination of miR-100 and antimir-32 had shown potential for the treatment of glioblastoma. In this case, both miRNAs have been incorporated onto gold-iron oxide NPs, functionalized with T7 peptide and $\beta$-cyclodextrin chitosan. The combination of intranasal administration of loaded gold-iron oxide NPs with systemic administration of temozolomide (TMZ) led to an increase in the survival time and magnetic resonance imaging properties, showing potential as a theragnostic agent [134].

In conclusion, different nanocarriers have been used that showed efficient nucleic acid delivery to the brain after intranasal administration. Overall, the tendency observed is that functionalized nanocarriers with targeting ligands or CPPs exhibit a greater performance compared to the nonfunctionalized ones.

\section{Conclusion and future perspectives}

Neurological disorders and the possible therapeutic strategies that would address them have been a subject of increased interest over the last decades. Among the different possibilities to successfully access the CNS, the main difficulty in this line of study, the use of nanocarriers has shown some potential for the direct N-to-B transport. Since the first successful attempt reported by Gao et al. in 2007, 
a variety of nanotechnological approaches have been developed and tested in animal models [141]. These approaches could be particularly beneficial for the N-to-B delivery of biomolecules, given that their access to the brain following systemic administration has proved extremely difficult so far.

In order to develop potential nanocarriers for the N-to-B transport of biomolecules, it is fundamental to take into consideration the different barriers that must be overcome and the way that nanocarriers can be specifically designed to overcome them. With regard to the physicochemical characteristics of the nanosystems, there is certain evidence that a small particle size correlates with an improved delivery of cargo from the nasal cavity to the brain. The majority of the nanocarriers explored present a mean diameter between $50-200 \mathrm{~nm}$; however, the smaller ones have, apparently, a greater chance to be transported to the brain. On the other hand, the influence of the surface charge in the N-to-B performance of nanocarriers is not that clear, although the majority of the nanocarriers reported to date exhibit a negative or neutral charge. Finally, the surface composition of the nanocarriers has an impact on their N-to-B transport. Of note, the use of permeation-enhancing molecules and the addition of PEGylated compounds have been reported to impact this transport. Moreover, the combination of these strategies with targeting ligands has also been reported as a promising strategy.

However, despite these promising findings and studies, none of these technologies intended for N-to-B delivery of biomolecules has reached the clinical development phase. This is understandable if we take into account the reduced number of in vivo studies performed to assess the value of these technologies. Moreover, an important drawback found in most of the relevant articles reporting in vivo results is the use of fluorescence imaging to confirm the presence of the drug in the brain after nasal administration. This type of imaging can be, in some cases, misleading and not a reliable quantitative approach for the determination of the amount of cargo delivered to the brain. Only a few studies have done a real quantification of the drug in different areas of the brain, to demonstrate the presence of the drug, and further studies need to be performed in order to confirm an adequate delivery. Importantly, it is not only fundamental to ensure an adequate transport of the macromolecules to the desired brain areas, but to ensure the maintenance of their functionality. In this regard, it would be critical to generate additional knowledge on the assessment of the pharmacokinetics and biodistribution of the therapeutic molecules in addition to their biological effect.

In conclusion, $\mathrm{N}$-to-B transport of biomolecules has been shown to be a potential alternative for the delivery of drug-loaded nanocarriers in sufficient amount to depict a therapeutic effect for the treatment of different neurological conditions. However, the application in the clinic of a combination of nanotechnology and N-to-B delivery is still at very early stages. To facilitate this promising translation, more studies to elucidate the suitable characteristics that a nanosystem must possess to be a successful carrier must be performed in more conclusive animal models, such as macaques. Furthermore, more conclusive data is needed regarding the pharmacodynamics and pharmacokinetics of the different pathways followed, as well as the biodistribution of the biomolecules in the brain.

Acknowledgements Mireya L. Borrajo acknowledges the financial support by Instituto de Salud Carlos III through the 'Contratos i-PFIS: Doctorados ISS-empresa en Ciencias y Tecnologías de la Salud' (IFI19/00033). The authors want to also acknowledge Jesús Fontán Dapena for assistance in the bibliographic search. Graphical abstract and Figures 1, 2, 5 and 6 were created with BioRender.com.

Author contribution Mireya L. Borrajo and María José Alonso contributed to writing, reviewing and editing the manuscript.

Funding Open Access funding provided thanks to the CRUE-CSIC agreement with Springer Nature. This work has been done within the European B-Smart Consortium, which received funding from the European Union's Horizon 2020 research and innovation program under grant agreement No 721058 .

Data Availability Not applicable.

\section{Declarations}

Ethics approval and consent to participate No ethics approval was required for this work.

Consent for publication The authors have read the final version and give their consents for the article to be published in Drug Delivery and Translational Research.

Competing interest The authors declare no competing interests.

Open Access This article is licensed under a Creative Commons Attribution 4.0 International License, which permits use, sharing, adaptation, distribution and reproduction in any medium or format, as long as you give appropriate credit to the original author(s) and the source, provide a link to the Creative Commons licence, and indicate if changes were made. The images or other third party material in this article are included in the article's Creative Commons licence, unless indicated otherwise in a credit line to the material. If material is not included in the article's Creative Commons licence and your intended use is not permitted by statutory regulation or exceeds the permitted use, you will need to obtain permission directly from the copyright holder. To view a copy of this licence, visit http://creativecommons.org/licenses/by/4.0/.

\section{References}

1. Prince M, Bryce R, Albanese E, Wimo A, Ribeiro W, Ferri CP. The global prevalence of apical periodontitis: a systematic review and meta-analysis. Alzheimer's Dement. 2013;9:63-75.

2. Olesen J, Gustavsson A, Svensson M, Wittchen HU, Jönsson B. The economic cost of brain disorders in Europe. Eur J Neurol. 2012;19:155-62. 
3. Hurd MD, Martorell P, Delavande A, Mullen KJ, Langa KM. Monetary costs of dementia in the United States. N Engl J Med. 2013;368:1326-34.

4. Craft S, Raman R, Chow TW, Rafii MS, Sun CK, Rissman RA, et al. Safety, efficacy, and feasibility of intranasal insulin for the treatment of mild cognitive impairment and Alzheimer disease dementia: a randomized clinical trial. JAMA Neurol. 2020;77:1099-109.

5. Morris JK, Burns JM. Insulin: an emerging treatment for Alzheimer's disease. Curr Neurol Neurosci Rep. 2013;12:520-7.

6. Berlanga-Acosta J, Guillén-Nieto G, Rodríguez-Rodríguez N, Bringas-Vega ML, García-del-Barco-Herrera D, BerlangaSaez JO, et al. Insulin resistance at the crossroad of Alzheimer disease pathology: a review. Front Endocrinol (Lausanne). 2020;11:1-22.

7. Cummings J, Aisen P, Lemere C, Atri A, Sabbagh M, Salloway S. Aducanumab produced a clinically meaningful benefit in association with amyloid lowering. Alzheimer's Res Ther. 2021;13:10-2.

8. U.S. Food and Drugs Administration. Center for drug evaluation and research. Aducanumab (marked as Aduhelm) Information. Acessed 09.06.21.

9. Kozlovskaya L, Abou-Kaoud M, Stepensky D. Quantitative analysis of drug delivery to the brain via nasal route. J Control Release. 2014;189:133-40.

10. Begley DJ. Delivery of therapeutic agents to the central nervous system: the problems and the possibilities. Pharmacol Ther. 2004;104:29-45.

11. Obermeier B, Daneman R, Ransohoff RM. Development, maintenance and disruption of blood-brain barrier. Nat Med. 2013;19:1584-96.

12. Warnken ZN, Smyth HDC, Watts AB, Weitman S, Kuhn JG, Williams RO. Formulation and device design to increase nose to brain drug delivery. J Drug Deliv Sci Technol. 2016;35:213-22.

13. Engelhardt B, Sorokin L. The blood-brain and the blood-cerebrospinal fluid barriers: function and dysfunction. Semin Immunopathol. 2009;31:497-511.

14. Lochhead JJ, Thorne RG. Intranasal delivery of biologics to the central nervous system. Adv Drug Deliv Rev. 2012;64:614-28.

15. Abbott NJ, Rönnbäck L, Hansson E. Astrocyte - endothelial interactions at the blood - brain barrier. Nat Rev Neurosci. 2006;7:41-53.

16. Persidsky Y, Ramirez SH, Haorah J, Kanmogne GD. Bloodbrain barrier: structural components and function under physiologic and pathologic conditions. J Neuroimmune Pharmacol. 2006;1:223-36.

17. Hersh DS, Wadajkar AS, Roberts N, Perez JG, Connolly NP, Frenkel V, et al. Evolving drug delivery strategies to overcome the blood brain barrier. Curr Pharm Des. 2016;22:1177-93.

18. Furtado D, Björnmalm M, Ayton S, Bush AI, Kempe K, Caruso F. Overcoming the blood-brain barrier: the role of nanomaterials in treating neurological diseases. Adv Mater. 2018;30.

19. Faber WM. The nasal mucosa and the subarachnoid space. Am J Anat. 1937;62:121-48.

20. Wu H, Hu K, Jiang X. From nose to brain: understanding transport capacity and transport rate of drugs. Expert Opin Drug Deliv. 2008;5:1159-68.

21. Djupesland PG, Messina JC, Mahmoud RA. The nasal approach to delivering treatment for brain diseases: an anatomic, physiologic, and delivery technology overview. Ther Deliv. 2014;5:709-33.

22. Bruinsmann FA, Vaz GR, De Cristo Soares Alves A, Aguirre T, Pohlmann AR, Guterres SS, et al. Nasal drug delivery of anticancer drugs for the treatment of glioblastoma: preclinical and clinical trials. Molecules. 2019;24.

23. Martins DA, Mazibuko N, Zelaya F, Vasilakopoulou S, Loveridge J, Oates A, et al. Effects of route of administration on oxytocin-induced changes in regional cerebral blood flow in humans. Nat Commun. 2020;11:1-16.

24. Dhuria SV, Hanson LR, Frey WH II. Intranasal delivery to the central nervous sytem: mechanisms and experimental consideration. J Pharm Sci Sci. 2010;99:2386-98.

25. Landis MS, Boyden T, Pegg S. Nasal-to-CNS drug delivery: where are we now and where are we heading? An industrial perspective Ther Deliv. 2012;3:195-208.

26. Pardeshi CV, Belgamwar VS. Direct nose to brain drug delivery via integrated nerve pathways bypassing the blood-brain barrier: an excellent platform for brain targeting. Expert Opin Drug Deliv. 2013;10:957-72.

27. Mittal D, Ali A, Md S, Baboota S, Sahni JK, Ali J. Insights into direct nose to brain delivery: current status and future perspective. Drug Deliv. 2014;21:75-86.

28. Samaridou E, Alonso MJ. Nose-to-brain peptide delivery - the potential of nanotechnology. Bioorganic Med Chem. 2018;26:2888-905.

29. Bourganis V, Kammona O, Alexopoulos A, Kiparissides C. Recent advances in carrier mediated nose-to-brain delivery of pharmaceutics. Eur J Pharm Biopharm. 2018;128:337-62.

30. Illum L. Transport of drugs from the nasal cavity to the central nervous system. Eur J Pharm Sci. 2000;11:1-18.

31. Kumar A, Pandey AN, Jain SK. Nasal-nanotechnology: revolution for efficient therapeutics delivery. Drug Deliv. 2016;23:681-93.

32. Ugwoke MI, Agu RU, Verbeke N, Kinget R. Nasal mucoadhesive drug delivery: background, applications, trends and future perspectives. Adv Drug Deliv Rev. 2005;57:1640-65.

33. Cone RA. Barrier properties of mucus. Adv Drug Deliv Rev. 2009;61:75-85.

34. Moran DT, Rowley JC, Jaferk BW, Lovell MA. The fine structure of the olfactory mucosa in man. J Neurocytol. 1982;11:721-46.

35. Gizurarson S. Anatomical and histological factors affecting intranasal drug and vaccine delivery. Curr Drug Deliv. 2012;9:566-82.

36. Mistry A, Stolnik S, Illum L. Nanoparticles for direct nose-tobrain delivery of drugs. Int J Pharm. 2009;379:146-57.

37. Gänger S, Schindowski K. Tailoring formulations for intranasal nose-to-brain delivery: a review on architecture, physico-chemical characteristics and mucociliary clearance of the nasal olfactory mucosa. Pharmaceutics. 2018;10:116.

38. Merkus FWHM, Van Den BMP. The blood-brain barrier? Questioning the direct transport theory. 2007;8:133-44.

39. Banks WA. Characteristics of compounds that cross the bloodbrain barrier. BMC Neurol. 2009;9:5-9.

40. Pardridge WM. Drug transport in brain via the cerebrospinal fluid. Fluids Barriers CNS. 2011;8:2-5.

41. Illum L. Is nose-to-brain transport of drugs in man a reality? J Pharm Pharmacol. 2004;56:3-17.

42. Hanson LR, Frey WH. Intranasal delivery bypasses the bloodbrain barrier to target therapeutic agents to the central nervous system and treat neurodegenerative disease. BMC Neurosci. 2008;9:1-4.

43. Mistry A, Stolnik S, Illum L. Nose-to-brain delivery: investigation of the transport of nanoparticles with different surface characteristics and sizes in excised porcine olfactory epithelium. Mol Pharm. 2015;12:2755-66.

44. Selvaraj K, Gowthamarajan K, Karri VVSR. Nose to brain transport pathways an overview: potential of nanostructured lipid carriers in nose to brain targeting. Artif Cells, Nanomedicine Biotechnol. 2018;46:2088-95.

45. Johnson NJ, Hanson LR, Frey WH. Trigeminal pathways deliver a low molecular weight drug from the nose to the brain and orofacial structures. Mol Pharm. 2010;7:884-93. 
46. Khan AR, Liu M, Khan MW, Zhai G. Progress in brain targeting drug delivery system by nasal route. J Control Release. 2017;268:364-89.

47. Finger TE, Böttger B, Schaefer ML, Silver WL. Trigeminal collaterals in the nasal epithelium and olfactory bulb: a potential route for direct modulation of olfactory information by trigeminal stimuli. J Comp Neurol. 2002;444:221-6.

48. Silver WL, Finger TE. The anatomical and electrophysiological basis of peripheral nasal trigeminal chemoreception. Ann N Y Acad Sci. 2009;1170:202-5.

49. Keller LA, Merkel O, Popp A. Intranasal drug delivery: opportunities and toxicologic challenges during drug development. Drug Deliv Transl Res. 2021.

50. Yamamoto A, Iseki T, Ochi-Sugiyama M, Okada N, Fujita T, Muranishi S. Absorption of water-soluble compounds with different molecular weights and [Asu1.7]-eel calcitonin from various mucosal administration sites. J Control Release. 2001;76:363-74.

51. Hill JM, Lesniak MA, Pert CB, Roth J. Autoradiographic localization of insulin receptors in rat brain: prominence in olfactory and limbic areas. Neuroscience. 1986;17:1127-38.

52. Unger J, McNeill TH, Moxley RT, White M, Moss A, Livingston JN. Distribution of insulin receptor-like immunoreactivity in the rat forebrain. Neuroscience. 1989;31:143-57.

53. Marks JL, Porte D, Stahl WL, Basking DG. Localization of insulin receptor mrna in rat brain by in situ hybridization. Endocrinology. 1990;127:3234-6.

54. Chen XQ, Fawcett JR, Rahman YE, Ala TA, Frey WH. Delivery of nerve growth factor to the brain via the olfactory pathway. $\mathrm{J}$ Alzheimer's Dis. 1998;1:35-44.

55. Quintana D, Rokicki J, van der Meer D, Alnæs D, Kaufmann $\mathrm{T}$, Palomera AC, et al. Oxytocin gene networks in the human brain: a gene expression and large-scale fMRI meta-analysis study. bioRxiv. 2017;149526.

56. Quintana DS, Smerud KT, Andreassen OA, Djupesland PG. Evidence for intranasal oxytocin delivery to the brain: recent advances and future perspectives. Ther Deliv. 2018;9:515-25.

57. Cole P. The four components of the nasal valve. Am J Rhinol. 2003;17:107-10.

58. Quintana DS, Guastella AJ, Westlye LT, Andreassen OA. The promise and pitfalls of intranasally administering psychopharmacological agents for the treatment of psychiatric disorders. Mol Psychiatry. 2016;21:29-38.

59. Quintana DS, Westlye LT, Alnæs D, Kaufmann T, Mahmoud RA, Smerud KT, et al. Low-dose intranasal oxytocin delivered with breath powered device modulates pupil diameter and amygdala activity: a randomized controlled pupillometry and fMRI study. Neuropsychopharmacology. 2019;44:306-13.

60. Smith TD, Bhatnagar KP, Tuladhar P, Burrows AM. Distribution of olfactory epithelium in the primate nasal cavity: are microsmia and macrosmia valid morphological concepts? Anat Rec - Part A Discov Mol Cell Evol Biol. 2004;281:1173-81.

61. Harkema JR, Carey SA, Wagner JG. The nose revisited: a brief review of the comparative structure, function, and toxicologic pathology of the nasal epithelium. Toxicol Pathol. 2006;34:252-69.

62. Cuschieri A. Enzyme histochemistry of the olfactory mucosa and vomeronasal organ in the mouse. J Anat. 1974;118:477-89.

63. Lee VHL, Yamamoto A. Penetration and enzymatic barriers to peptide and protein absorption. Adv Drug Deliv Rev. 1989;4:171-207.

64. Hu J, Sheng L, Li L, Zhou X, Xie F, D’Agostino J, et al. Essential role of the cytochrome P450 enzyme CYP2A5 in olfactory mucosal toxicity of naphthalene. Drug Metab Dispos. 2014;42:23-7.

65. Anand U, Parikh A, Ugwu MC, Agu RU. Drug transporters in the nasal epithelium: an overview of strategies in targeted drug delivery. Future Med Chem. 2014;6:1381-9.
66. Graff CL, Pollack GM. Functional evidence for P-glycoprotein at the nose-brain barrier. Pharm Res. 2005;22:86-93.

67. Tillerson JL, Caudle WM, Parent JM, Gong C, Schallert T, Miller GW. Olfactory discrimination deficits in mice lacking the dopamine transporter or the D2 dopamine receptor. Behav Brain Res. 2006;172:97-105.

68. Hussar P, Tserentsoodol N, Koyama H, Yokoo-Sugawara M, Matsuzaki T, Takami S, et al. The glucose transporter GLUT1 and the tight junction protein occludin in nasal olfactory mucosa. Chem Senses. 2002;27:7-11.

69. Hanson LR, Fine JM, Svitak AL, Faltesek KA. Intranasal administration of CNS therapeutics to awake mice. J Vis Exp. $2013 ; 4440$.

70. Van Woensel M, Wauthoz N, Rosière R, Amighi K, Mathieu V, Lefranc F, et al. Formulations for intranasal delivery of pharmacological agents to combat brain disease: a new opportunity to tackle GBM? Cancers (Basel). 2013;5:1020-48.

71. ClinicalTrials Database. US National Library of Medicine. National Institutes of Health. Accessed 21.05.21.

72. Craft S, Baker LD, Montine TJ, Minoshima S, Watson GS, Claxton A, et al. Intranasal insulin therapy for Alzheimer disease and amnestic mild cognitive impairment: a pilot clinical trial. Arch Neurol. 2012;69:29-38.

73. Rosenbloom M, Barclay TR, Kashyap B, Hage L, O'Keefe LR, Svitak A, et al. A phase II, single-center, randomized, double-blind, placebo-controlled study of the safety and therapeutic efficacy of intranasal glulisine in amnestic mild cognitive impairment and probable mild Alzheimer's disease. Drugs Aging. 2021;38:407-15.

74. Kullmann S, Heni M, Veit R, Scheffler K, Machann J, Haring $\mathrm{HU}$, et al. Selective insulin resistance in homeostatic and cognitivecontrol brain areas in overweight and obese adults. Diabetes Care. 2015;38:1044-50.

75. Heni M, Wagner R, Willmann C, Jaghutriz BA, Vosseler A, Kübler C, et al. Insulin action in the hypothalamus increases second-phase insulin secretion in humans. Neuroendocrinology. 2020;110:929-37.

76. Tabak BA, Meyer ML, Castle E, Dutcher JM, Irwin MR, Han $\mathrm{JH}$, et al. Vasopressin, but not oxytocin, increases empathic concern among individuals who received higher levels of paternal warmth: a randomized controlled trial. Psychoneuroendocrinology. 2015;51:253-61.

77. Tabak BA, Teed AR, Castle E, Dutcher JM, Meyer ML, Bryan $\mathrm{R}$, et al. Null results of oxytocin and vasopressin administration across a range of social cognitive and behavioral paradigms: evidence from a randomized controlled trial. Psychoneuroendocrinology. 2019;107:124-32.

78. Price D, Burris D, Cloutier A, Thompson CB, Rilling JK, Thompson RR. Dose-dependent and lasting influences of intranasal vasopressin on face processing in men. Front Endocrinol (Lausanne). 2017;8:1-15.

79. Scopus Database. Elservier. Accessed 06.04.21.

80. PubMed Database. US National Library of Medicine. National Institutes of Health. Accessed 06.04.21.

81. Trevino J, Quispe R, Khan F, Novak V. Non-invasive strategies for nose-to-brain drug delivery. J Clin Trials. 2020;10:439.

82. Wang Z, Xiong G, Tsang WC, Schätzlein AG, Uchegbu IF. Noseto-brain delivery. J Pharmacol Exp Ther. 2019;370:593-601.

83. Agrawal M, Saraf S, Saraf S, Antimisiaris SG, Chougule MB, Shoyele SA, et al. Nose-to-brain drug delivery: an update on clinical challenges and progress towards approval of anti-Alzheimer drugs. J Control Release [Internet]. Elsevier; 2018;281:139-77. Available from: https://doi.org/10.1016/j.jconrel.2018.05.011

84. Bonferoni MC, Rossi S, Sandri G, Ferrari F, Gavini E, Rassu G, et al. Nanoemulsions for "nose-to-brain" drug delivery. Pharmaceutics. 2019;11:1-17. 
85. Kim YS, Sung DK, Kim H, Kong WH, Kim YE, Hahn SK. Noseto-brain delivery of hyaluronate - FG loop peptide conjugate for non-invasive hypoxic-ischemic encephalopathy therapy. J Control Release. 2019;307:76-89.

86. Vllasaliu D, Exposito-Harris R, Heras A, Casettari L, Garnett $\mathrm{M}$, Illum L, et al. Tight junction modulation by chitosan nanoparticles: comparison with chitosan solution. Int J Pharm. 2010;400:183-93.

87. Casettari L, Illum L. Chitosan in nasal delivery systems for therapeutic drugs. J Control Release. 2014;190:189-200.

88. Vaka SRK, Murthy SN, Balaji A, Repka MA. Delivery of brainderived neurotrophic factor via nose-to-brain pathway. Pharm Res. 2012;29:441-7.

89. Derakhshankhah H, Jafari S. Cell penetrating peptides: a concise review with emphasis on biomedical applications. Biomed Pharmacother. 2018;108:1090-6.

90. Trabulo S, Cardoso AL, Mano M, De Lima MCP. Cell-penetrating peptides-mechanisms of cellular uptake and generation of delivery systems. Pharmaceuticals. 2010;3:961-93.

91. Jafari S, Maleki Dizaj S, Adibkia K. Cell-penetrating peptides and their analogues as novel nanocarriers for drug delivery. BioImpacts. 2017;5:103-11.

92. Guidotti G, Brambilla L, Rossi D. Cell-penetrating peptides: from basic research to clinics. Trends Pharmacol Sci. 2017;38:406-24.

93. Derossi D, Joliot AH, Chassaing G, Prochiantz A. The third helix of the Antennapedia homeodomain translocates through biological membranes. J Biol Chem. 1994;269:10444-50.

94. Thorén PEG, Persson D, Karlsson M, Nordén B. The Antennapedia peptide penetratin translocates across lipid bilayers - the first direct observation. FEBS Lett. 2000;482:265-8.

95. Dupont E, Prochiantz A, Joliot A. Penetratin story: an overview. Methods Mol Biol. 2015;1324:29-37.

96. Kamei N, Shingaki T, Kanayama Y, Tanaka M, Zochi R, Hasegawa $\mathrm{K}$, et al. Visualization and quantitative assessment of the brain distribution of insulin through nose-to-brain delivery based on the cell-penetrating peptide noncovalent strategy. Mol Pharm. 2016;13:1004-11.

97. Kamei N, Tanaka M, Choi H, Okada N, Ikeda T, Itokazu R, et al. Effect of an enhanced nose-to-brain delivery of insulin on mild and progressive memory loss in the senescence-accelerated mouse. Mol Pharm. 2017;14:916-27.

98. Kamei N, Okada N, Ikeda T, Choi H, Fujiwara Y, Okumura H, et al. Effective nose-to-brain delivery of exendin-4 via coadministration with cell-penetrating peptides for improving progressive cognitive dysfunction. Sci Rep. 2018;8:1-14.

99. Lin T, Liu E, He H, Shin MC, Moon C, Yang VC, et al. Nose-tobrain delivery of macromolecules mediated by cell-penetrating peptides. Acta Pharm Sin B. 2016;6:352-8.

100. Miwa T, Tachii K, Wei FY, Kaitsuka T, Tomizawa K. Intranasal drug delivery into mouse nasal mucosa and brain utilizing argininerich cell-penetrating peptide-mediated protein transduction. Int J Pept Res Ther. 2020;26:1643-50.

101. Yuan D, Yi X, Zhao Y, Poon CD, Bullock KM, Hansen KM, et al. Intranasal delivery of $\mathrm{N}$-terminal modified leptin-pluronic conjugate for treatment of obesity. J Control Release. 2017;263:172-84.

102. Yu H, Kim K. Direct nose-to-brain transfer of a growth hormone releasing neuropeptide, hexarelin after intranasal administration to rabbits. Int J Pharm. 2009;378:73-9.

103. Ye D, Raghnaill MN, Bramini M, Mahon E, Åberg C, Salvati A, et al. Nanoparticle accumulation and transcytosis in brain endothelial cell layers. Nanoscale. 2013;5:11153-65.

104. Fullstone G, Nyberg S, Tian X, Battaglia G. From the blood to the central nervous system: a nanoparticle's journey through the blood-brain barrier by transcytosis. Int Rev Neurobiol. 2016.

105. Pulgar VM. Transcytosis to cross the blood brain barrier, new advancements and challenges. Front Neurosci. 2019;13:1-9.
106. Morrison EE, Costanzo RM. Morphology of olfactory epithelium in humans and other vertebrates. Microsc Res Tech. 1992;23:49-61.

107. Kumar M, Pandey RS, Patra KC, Jain SK, Soni ML, Dangi JS, et al. Evaluation of neuropeptide loaded trimethyl chitosan nanoparticles for nose to brain delivery. Int J Biol Macromol. 2013;61:189-95

108. Yadav S, Gattacceca F, Panicucci R, Amiji MM. Comparative biodistribution and pharmacokinetic analysis of cyclosporine-A in the brain upon intranasal or intravenous administration in an oil-inwater nanoemulsion formulation. Mol Pharm. 2015;12:1523-33.

109. Manickavasagam D, Lin L, Oyewumi MO. Nose-to-brain codelivery of repurposed simvastatin and BDNF synergistically attenuates LPS-induced neuroinflammation. Nanomedicine Nanotechnology, Biol Med. 2020;23:102107.

110. Kubek MJ, Domb AJ, Veronesi MC. Attenuation of kindled seizures by intranasal delivery of neuropeptide-loaded nanoparticles. Neurotherapeutics. 2009;6:359-71.

111. Ahmad E, Feng Y, Qi J, Fan W, Ma Y, He H, et al. Evidence of nose-to-brain delivery of nanoemulsions: cargoes but not vehicles. Nanoscale. 2017;9:1174-83.

112. Mistry A, Glud SZ, Kjems J, Randel J, Howard KA, Stolnik S, et al. Effect of physicochemical properties on intranasal nanoparticle transit into murine olfactory epithelium. J Drug Target. 2009; $17: 543-52$

113. Sava V, Fihurka O, Khvorova A, Sanchez-Ramos J. Enriched chitosan nanoparticles loaded with siRNA are effective in lowering Huntington's disease gene expression following intranasal administration. Nanomedicine Nanotechnology, Biol Med. 2020;24:102119.

114. Zhao YZ, Jin RR, Yang W, Xiang Q, Yu WZ, Lin Q, et al. Using gelatin nanoparticle mediated intranasal delivery of neuropeptide substance $\mathrm{P}$ to enhance neuro-recovery in hemiparkinsonian rats. PLoS ONE. 2016;11:1-18.

115. Zhao YZ, Li X, Lu CT, Lin M, Chen LJ, Xiang Q, et al. Gelatin nanostructured lipid carriers-mediated intranasal delivery of basic fibroblast growth factor enhances functional recovery in hemiparkinsonian rats. Nanomedicine Nanotechnology, Biol Med. 2014;10:755-64.

116. Bonaccorso A, Musumeci T, Serapide MF, Pellitteri R, Uchegbu IF, Puglisi G. Nose to brain delivery in rats: effect of surface charge of rhodamine B labeled nanocarriers on brain subregion localization. Colloids Surfaces B Biointerfaces. 2017;154:297-306.

117. Perez AP, Mundiña-Weilenmann C, Romero EL, Morilla MJ. Increased brain radioactivity by intranasal 32P-labeled siRNA dendriplexes within in situ-forming mucoadhesive gels. Int $\mathbf{J}$ Nanomedicine. 2012;7:1373-85.

118. Alsarra IA, Hamed AY, Mahrous GM, El Maghraby GM, AlRobayan AA, Alanazi FK. Mucoadhesive polymeric hydrogels for nasal delivery of acyclovir. Drug Dev Ind Pharm. 2009;35:352-62.

119. Picone P, Sabatino MA, Ditta LA, Amato A, San Biagio PL, Mulè F, et al. Nose-to-brain delivery of insulin enhanced by a nanogel carrier. J Control Release. 2018;270:23-36.

120. Frankel AD, Pabo CO. Cellular uptake of the tat protein from human immunodeficiency virus. Cell Cell Press. 1988;55:1189-93.

121. Vivès E, Brodin P, Lebleu B. A truncated HIV-1 Tat protein basic domain rapidly translocates through the plasma membrane and accumulates in the cell nucleus. J Biol Chem. 1997;272:16010-7.

122. Park J, Ryu J, Kim K-A, Lee HJ, Bahn JH, Han K, et al. Mutational analysis of a human immunodeficiency virus type 1 Tat protein transduction domain which is required for delivery of an exogenous protein into mammalian cells. J Gen Virol. 2002;83:1173-81. 
123. Yan L, Wang H, Jiang Y, Liu J, Wang Z, Yang Y, et al. Cellpenetrating peptide-modified PLGA nanoparticles for enhanced nose-to-brain macromolecular delivery. Macromol Res. 2013;21:435-41.

124. Kanazawa T, Akiyama F, Kakizaki S, Takashima Y, Seta Y. Delivery of siRNA to the brain using a combination of noseto-brain delivery and cell-penetrating peptide-modified nanomicelles. Biomaterials. 2013;34:9220-6.

125. Kanazawa T, Morisaki K, Suzuki S, Takashima Y. Prolongation of life in rats with malignant glioma by intranasal siRNA/drug codelivery to the brain with cell-penetrating peptide-modified micelles. Mol Pharm. 2014;11:1471-8.

126. Kanazawa T, Kurano T, Ibaraki H, Takashima Y, Suzuki T, Seta Y. Therapeutic effects in a transientmiddle cerebral artery occlusion ratmodel by nose-to-brain delivery of anti-TNF-alpha siRNA with cell-penetrating peptide-modified polymer micelles. Pharmaceutics. 2019;11:478.

127. Ahmad E, Lv Y, Zhu Q, Qi J, Dong X, Zhao W, et al. TAT modification facilitates nose-to-brain transport of intact $\mathrm{mPEG}$ PDLLA micelles: evidence from aggregation-caused quenching probes. Appl Mater Today. 2020;19.

128. Xia H, Gao X, Gu G, Liu Z, Zeng N, Hu Q, et al. Low molecular weight protamine-functionalized nanoparticles for drug delivery to the brain after intranasal administration. Biomaterials. 2011;32:9888-98.

129. Kanazawa T, Kaneko M, Niide T, Akiyama F, Kakizaki S, Ibaraki $\mathrm{H}$, et al. Enhancement of nose-to-brain delivery of hydrophilic macromolecules with stearate- or polyethylene glycol-modified arginine-rich peptide. Int J Pharm. 2017;530:195-200.

130. Samaridou E, Walgrave H, Salta E, Álvarez DM, Castro-López V, Loza M, et al. Nose-to-brain delivery of enveloped RNA - cell permeating peptide nanocomplexes for the treatment of neurodegenerative diseases. Biomaterials. 2020;230:119657.

131. Xie J, Bi Y, Zhang H, Dong S, Teng L, Lee RJ, et al. Cell-penetrating peptides in diagnosis and treatment of human diseases: from preclinical research to clinical application. Front Pharmacol. 2020;11:1-23.

132. Zhang Y, Guo P, Ma Z, Lu P, Kebebe D, Liu Z. Combination of cell-penetrating peptides with nanomaterials for the potential therapeutics of central nervous system disorders: a review. $\mathbf{J}$ Nanobiotechnology. 2021;19:1-22.

133. Van Woensel M, Mathivet $\mathrm{T}$, Wauthoz N, Rosière R, Garg AD, Agostinis $\mathrm{P}$, et al. Sensitization of glioblastoma tumor microenvironment to chemo- and immunotherapy by Galectin-1 intranasal knock-down strategy. Sci Rep. 2017;7:1-14.

134. Sukumar UK, Bose RJC, Malhotra M, Babikir HA, Afjei R, Robinson E, et al. Intranasal delivery of targeted polyfunctional gold-iron oxide nanoparticles loaded with therapeutic microRNAs for combined theranostic multimodality imaging and presensitization of glioblastoma to temozolomide. Biomaterials. 2019;218:119342.

135. Sanchez-Ramos J, Song S, Kong X, Foroutan P, Martinez G, Dominguez-Viqueria W, et al. Chitosan-Mangafodipir nanoparticles designed for intranasal delivery of siRNA and DNA to brain. J Drug Deliv Sci Technol. 2018;43:453-60.

136. Gartziandia O, Herran E, Pedraz JL, Carro E, Igartua M, Hernandez RM. Chitosan coated nanostructured lipid carriers for brain delivery of proteins by intranasal administration. Colloids Surfaces B Biointerfaces. 2015;134:304-13.

137. Gartziandia O, Herrán E, Ruiz-Ortega JA, Miguelez C, Igartua $\mathrm{M}$, Lafuente JV, et al. Intranasal administration of chitosan-coated nanostructured lipid carriers loaded with GDNF improves behavioral and histological recovery in a partial lesion model of Parkinson's disease. J Biomed Nanotechnol. 2016;12:2220-30.

138. Schwab ME, Javoy-Agid F, Agid Y. Labeled wheat germ agglutinin (WGA) as a new, highly sensitive retrograde tracer in the rat brain hippocampal system. Brain Res. 1978;152:145-50.
139. Banks WA, Broadwell RD. Blood to brain and brain to blood passage of native horseradish peroxidase, wheat germ agglutinin, and albumin: pharmacokinetic and morphological assessments. J Neurochem. 1994;62:2404-19.

140. Wirth M, Hamilton G, Gabor F. Lectin-mediated drug targeting: quantification of binding and internalization of wheat germ agglutinin and Solanum tuberosum lectin using Caco-2 and HT-29 cells. J Drug Target. 1998;6:95-104.

141. Gao X, Wu B, Zhang Q, Chen J, Zhu J, Zhang W, et al. Brain delivery of vasoactive intestinal peptide enhanced with the nanoparticles conjugated with wheat germ agglutinin following intranasal administration. J Control Release. 2007;121:156-67.

142. Liu Q, Shen Y, Chen J, Gao X, Feng C, Wang L, et al. Nose-tobrain transport pathways of wheat germ agglutinin conjugated PEG-PLA nanoparticles. Pharm Res. 2012;29:546-58.

143. Su Y, Sun B, Gao X, Dong X, Fu L, Zhang Y, et al. Intranasal delivery of targeted nanoparticles loaded with miR-132 to brain for the treatment of neurodegenerative diseases. Front Pharmacol. 2020;11:1-13.

144. Li R, Huang Y, Chen L, Zhou H, Zhang M, Chang L, et al. Targeted delivery of intranasally administered nanoparticles-mediated neuroprotective peptide NR2B9c to brain and neuron for treatment of ischemic stroke. Nanomedicine Nanotechnology, Biol Med. 2019;18:380-90.

145. Lundh B, Brockstedt U, Kristensson K. Lectin-binding pattern of neuroepithelial and respiratory epithelial cells in the mouse nasal cavity. Histochem J. 1989;21:33-43.

146. Chen J, Zhang C, Liu Q, Shao X, Feng C, Shen Y, et al. Solanum tuberosum lectin-conjugated PLGA nanoparticles for nose-tobrain delivery: in vivo and in vitro evaluations. J Drug Target. 2012;20:174-84.

147. Zhang C, Chen J, Feng C, Shao X, Liu Q, Zhang Q, et al. Intranasal nanoparticles of basic fibroblast growth factor for brain delivery to treat Alzheimer's disease. Int J Pharm. 2014;461:192-202.

148. Li J, Wu H, Hong J, Xu X, Yang H, Wu B, et al. Odorranalectin is a small peptide lectin with potential for drug delivery and targeting. PLoS One. 2008;3:e2381.

149. Wen Z, Yan Z, He R, Pang Z, Guo L, Qian Y, et al. Brain targeting and toxicity study of odorranalectin-conjugated nanoparticles following intranasal administration. Drug Deliv. 2011;18:555-61.

150. Wen Z, Yan Z, Hu K, Pang Z, Cheng X, Guo L, et al. Odorranalectinconjugated nanoparticles: preparation, brain delivery and pharmacodynamic study on Parkinson's disease following intranasal administration. J Control Release. 2011;151:131-8.

151. Wu H, Li J, Zhang Q, Yan X, Guo L, Gao X, et al. A novel small Odorranalectin-bearing cubosomes: preparation, brain delivery and pharmacodynamic study on amyloid- $\beta$ 25-35-treated rats following intranasal administration. Eur J Pharm Biopharm. 2012;80:368-78.

152. Huang R, Ke W, Qu Y, Zhu J, Pei Y, Jiang C. Characterization of lactoferrin receptor in brain endothelial capillary cells and mouse brain. J Biomed Sci. 2007;14:121-8.

153. Huang R, Ke W, Liu Y, Jiang C, Pei Y. The use of lactoferrin as a ligand for targeting the polyamidoamine-based gene delivery system to the brain. Biomaterials. 2008;29:238-46.

154. Agrawal M, Saraf S, Saraf S, Dubey SK, Puri A, Patel RJ, et al. Recent strategies and advances in the fabrication of nano lipid carriers and their application towards brain targeting. J Control Release. 2020;321:372-415.

155. Liu Z, Jiang M, Kang T, Miao D, Gu G, Song Q, et al. Lactoferrinmodified PEG-co-PCL nanoparticles for enhanced brain delivery of NAP peptide following intranasal administration. Biomaterials. 2013;34:3870-81.

156. Oswald M, Geissler S, Goepferich A. Targeting the central nervous system (CNS): a review of rabies virus-targeting strategies. Mol Pharm. 2017;14:2177-96. 
157. Hao R, Sun B, Yang L, Ma C, Li S. RVG29-modified microRNAloaded nanoparticles improve ischemic brain injury by nasal delivery. Drug Deliv. 2020;27:772-81.

158. Gallardo-Toledo E, Tapia-Arellano A, Celis F, Sinai T, Campos $\mathrm{M}$, Kogan MJ, et al. Intranasal administration of gold nanoparticles designed to target the central nervous system: fabrication and comparison between nanospheres and nanoprisms. Int $\mathbf{J}$ Pharm. 2020;590:119957.

159. Pan L, Zhou J, Ju F, Zhu H. Intranasal delivery of $\alpha$-asarone to the brain with lactoferrin-modified mPEG-PLA nanoparticles prepared by premix membrane emulsification. Drug Deliv Transl Res. 2018;8:83-96.

160. Bi CC, Wang AP, Chu YC, Liu S, Mu HJ, Liu WH, et al. Intranasal delivery of rotigotine to the brain with lactoferrin-modified PEG-PLGA nanoparticles for Parkinson's disease treatment. Int J Nanomedicine. 2016;11:6547-59.

161. Yan X, Xu L, Bi C, Duan D, Chu L, Yu X, et al. Lactoferrinmodified rotigotine nanoparticles for enhanced nose-to-brain delivery: LESA-MS/MS-based drug biodistribution, pharmacodynamics, and neuroprotective effects. Int J Nanomedicine. 2018;13:273-81.

162. Tang S, Wang A, Yan X, Chu L, Yang X, Song Y, et al. Braintargeted intranasal delivery of dopamine with borneol and lactoferrin co-modified nanoparticles for treating Parkinson's disease. Drug Deliv. 2019;26:700-7.

163. Meng Q, Wang A, Hua H, Jiang Y, Wang Y, Mu H, et al. Intranasal delivery of Huperzine A to the brain using lactoferrinconjugated $\mathrm{N}$-trimethylated chitosan surface-modified PLGA nanoparticles for treatment of Alzheimer's disease. Int J Nanomedicine. 2018;13:705-18.

164. Re F, Gregori M, Masserini M. Nanotechnology for neurodegenerative disorders. Maturitas. 2012;73:45-51.

165. Teleanu DM, Chircov C, Grumezescu AM, Volceanov A, Teleanu RI. Blood-brain delivery methods using nanotechnology Pharmaceutics. 2018;10:1-16.

166. Kumar A, Chaudhary RK, Singh R, Singh SP, Wang SY, Hoe ZY, et al. Nanotheranostic applications for detection and targeting neurodegenerative diseases. Front Neurosci. 2020;14:1-11.

167. Tiwari S, Chaturvedi R. Peptide therapeutics in neurodegenerative disorders. Curr Med Chem. 2014;21:2610-31.

168. Baig MH, Ahmad K, Saeed M, Alharbi AM, Barreto GE, Ashraf GM, et al. Peptide based therapeutics and their use for the treatment of neurodegenerative and other diseases. Biomed Pharmacother. 2018;103:574-81.

169. Guidotti G, Brambilla L, Rossi D. Peptides in clinical development for the treatment of brain tumors. Curr Opin Pharmacol. 2019;47:102-9.
170. Narayanaswamy R, Wang T, P. Torchilin V. Improving peptide applications using nanotechnology. Curr Top Med Chem. 2015;16:253-70.

171. Spencer BJ, Verma IM. Targeted delivery of proteins across the blood-brain barrier. Proc Natl Acad Sci U S A. 2007;104:7594-9.

172. Pardridge WM. Blood-brain barrier and delivery of protein and gene therapeutics to brain. Front Aging Neurosci. 2020;11:1-27.

173. Zhao YZ, Lin M, Lin Q, Yang W, Yu XC, Tian FR, et al. Intranasal delivery of bFGF with nanoliposomes enhances in vivo neuroprotection and neural injury recovery in a rodent stroke model. J Control Release. 2016;224:165-75.

174. Nelson AL, Dhimolea E, Reichert JM. Development trends for human monoclonal antibody therapeutics. Nat Rev Drug Discov. 2010;9:767-74.

175. Buss NAPS, Henderson SJ, McFarlane M, Shenton JM, De Haan L. Monoclonal antibody therapeutics: history and future. Curr Opin Pharmacol. 2012;12:615-22.

176. Elgundi Z, Reslan M, Cruz E, Sifniotis V, Kayser V. The stateof-play and future of antibody therapeutics. Adv Drug Deliv Rev. 2017;122:2-19.

177. Chu L, Wanga A, Ni L, Yan X, Song Y, Zhao M, et al. Noseto-brain delivery of temozolomide-loaded PLGA nanoparticles functionalized with anti-EPHA3 for glioblastoma targeting. Drug Deliv. 2018;25:1634-41.

178. Mathupala SP. Delivery of small-interfering RNA (siRNA) to the brain. Expert Opin Ther Pat. 2009;19:137-40.

179. Wen MM. Getting miRNA therapeutics into the target cells for neurodegenerative diseases: a mini-review. Front Mol Neurosci. 2016;9:129.

180. Davidson BL. Doubling down on siRNAs in the brain. Nat Biotechnol. 2019;37:865-6.

181. Lee SWL, Paoletti C, Campisi M, Osaki T, Adriani G, Kamm RD, et al. MicroRNA delivery through nanoparticles. J Control Release. 2019;313:80-95.

182. Van Woensel M, Wauthoz N, Rosière R, Mathieu V, Kiss R, Lefranc F, et al. Development of siRNA-loaded chitosan nanoparticles targeting Galectin-1 for the treatment of glioblastoma multiforme via intranasal administration. J Control Release. 2016;227:71-81.

Publisher's Note Springer Nature remains neutral with regard to jurisdictional claims in published maps and institutional affiliations. 